\title{
CONCURRENT STUDIES OF ENHANCED HEAT TRANSFER AND MATERIALS FOR OCEAN THERMAL HEAT EXCHANGERS
}

Period Covered

March 1, 1978 to August 31, 1978

\author{
Prepared by \\ Robert R. Rothfus \\ Principal Investigator \\ Arthur W. Westerberg \\ Co-Principal Investigator \\ Shichune Yao \\ N.H. Chao \\ S. Kuru \\ Carnegie Mellon University \\ Pittsburgh, Pennsylvania 15213
}

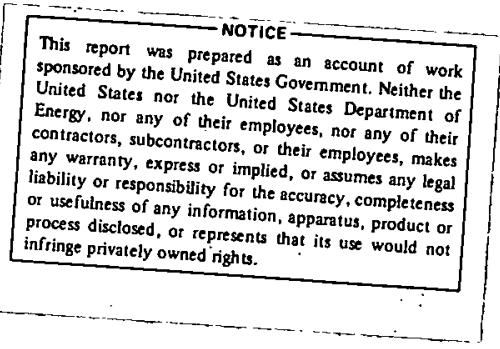

September 1978

This work has been supported by the Department of Energy, Division of Solar Technology, under Contract No. EY-76-S-02-2641, initiated May 1, 1975.

Caveat: All conclusions, opinions, findings or recommendations expressed herein are those of the authors and do not necessarily reflect the views of the United States Government or the Department of Energy. 


\section{DISCLAIMER}

This report was prepared as an account of work sponsored by an agency of the United States Government. Neither the United States Government nor any agency Thereof, nor any of their employees, makes any warranty, express or implied, or assumes any legal liability or responsibility for the accuracy, completeness, or usefulness of any information, apparatus, product, or process disclosed, or represents that its use would not infringe privately owned rights. Reference herein to any specific commercial product, process, or service by trade name, trademark, manufacturer, or otherwise does not necessarily constitute or imply its endorsement, recommendation, or favoring by the United States Government or any agency thereof. The views and opinions of authors expressed herein do not necessarily state or reflect those of the United States Government or any agency thereof. 


\section{DISCLAIMER}

Portions of this document may be illegible in electronic image products. Images are produced from the best available original document. 
SEMI-ANNUAL PROGRESS REPORT

DOE CONTRACT NO. EY-76-S-02-2641

PART I

DYNAMIC AND CONTROL SYSTEM MODELING

THE OSCAR SYSTEM

For Period

March 1, 1978 through August 31, 1978

\author{
Prepared by \\ Arthur W. Westerberg \\ Co-Principal Investigator \\ Shichune Yao \\ N.H. Chao \\ S. Kuru \\ Carnegie-Mellon University \\ Pittsburgh, Pennsylvania 15213
}

September 1978 
1. Introduction. .............................. 1

1.1 scenario..................................... 3

1.2 Report Contents.............................. 5

2. Functional specifications for OSCAR $-1 \ldots \ldots \ldots \ldots \ldots \ldots \ldots$

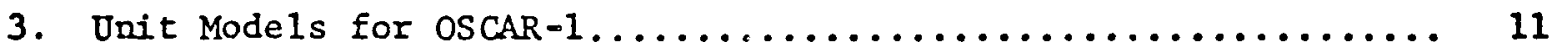

3.1 Simple stream Splitter......................... 11

3.2 Stream Mixer tnit.............................. 13

3.3 valve..................................... 12

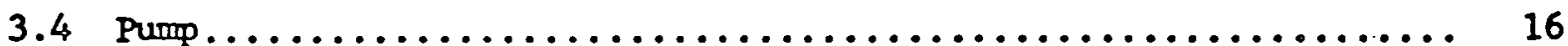

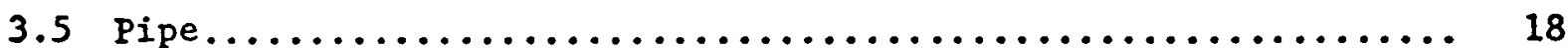

3.6 Turbine ..................................... 21

3.7 Evaporators and Condensers........................ 22

3.7 .1 Nomenclature................................. 22

3.7 .2 Introduction.................................. 24

3.7.3 Fundamental Behavior of the Liquid Film................ 27

3.7.4 Dynamic Modeling of the LIquid Film.................... 32

3.7.5 Dynamic Modeling of the Heat Exchangers................. 35

3.7.6 Further Refinement of the Mode1.................... 47

3.7 .7 References for section $3.7 \ldots \ldots \ldots \ldots \ldots \ldots \ldots \ldots \ldots \ldots \ldots \ldots \ldots$

3.8 PI Controller................................. 49

4. Software System Design for OSCAR $-1 \ldots \ldots \ldots \ldots \ldots \ldots \ldots \ldots \ldots \ldots$

4.1 Introduction. ............................... 51

4.2 Abstract Dynamic and Steady-State Mode1............... 52

4.3 The Newton-Raphson Method.......................... 54

4.4 System View of OSCAR-1......................... 57

4.5 Generators and Packets.......................... 60

4.6 Arbitrary User Specifications..................... 66

4.7 Simplifying User Input......................... 66

4.8 Dynamic System Design........................ 67

Appendix.................................. 68 
1. Introduction

This report covers the work accomplished to date for DOE Contract EY-76-S-02-2641-A004 by the group headed by Arthur $W$. Westerberg. The task to be accomplished by this effort is to deliver a program (now called OSCAR (OTEC Steady-state and Control System Analysis Routines)) to perform dynamic simulations for arbitrarily configured OTEC plants. The expected completion date for the first version of OSCAR is March 1, 1979. The current personnel working on the OSCAR project are listed in Table 1.

A.W. Westerberg: Professor of Chemical Engineering and Director of Design Research Center

Working on System Design for OSCAR

S. Yao: Assistant Professor of Mechanical Engineering Working on Evaporator/Condenser Models
N. Chao
Graduate Students at $\mathrm{Ph} . \mathrm{D}$. leve1
S. Kuru Working on aspects of OSCAR in
M. Locke support of two faculty members.

Table 1. Personnel on Project

As an effective effort to the overall OTEC development, it appears that the basic features of a successful dynamic simulation have to include the following. 
(1) The simulation program will be flexible enough to study any of the OTEC plant designs which are proposed by different design groups with different combinations of the components. In addition, the modeling of the evaporators and condensers has to be also general enough to accommodate various design concepts (for example, vertical or horizontal tube bundles).

(2) The range of the operating conditions which the program similates must be wide enough to cover both the severe transients at emergency conditions as well as the normal operating condition. With this capability, proper control schemes may be developed to handle both the normal and the emergency operations.

The OSCAR program is developed to contain these features. The goal is to produce a tool for engineers who are studying design alternatives for OTEC plants so they can perform dynamic simulations to assess the operation of proposed control schemes.

Because the control schemes for OTEC appear to be largely influenced by the need to control in the face of large transients and even during emergency trip situations, the OSCAR system must be able to simulate plant performance over very wide operating ranges. This requirement dictates that the models are nonlinear in nature; in fact, they even have to contain discontinuities (a liquid may stop bolling). Also it requires that the approach taken to simulate a system comprising such models must be able to withstand the numerical difficulties which arise because of these discontinuities and nonlinearities. 


\subsection{Scenario}

We anticipate the following scenario as possible for using OSCAR. The scenario will expose the steps needed to perform a successful dynamic simulation and, more importantly, to make comvenient use of OSCAR in the design process. Scenario: "The engineer has just developed a configuration for a proposed OTEC plant. The plant consists of two parallel condensers, three turbines, two evaporators, recirculation lines to recirculate the working fluid $\left(\mathrm{NH}_{3}\right)$ from the "hot well" storage at the bottom of each evaporator back around as feed to the evaporator, etc.

To control the plant, a vapor by-pass line and valve is used to permit by-pass of the turbines. Also variable speed motors are being used to control the water flow into the evaporators. This scheme represents one of many alternatives he has in mind.

Looking at the user's manual for OSCAR, the engineer finds each piece of equipment he wishes to use has a counterpart model already in OSCAR, except one. He wants a different type of valve in his system which he feels OSCAR will not adequately model. The modular design of OSCAR permits this problem to be addressed in a straightrorward manner, with the instructions given in the manual as to how to produce a new module for inclusion into OSCAR. He finds he must write several quite simple FORTRAN subroutines - one to tell the OSCAR system the number of modeling equations, one to establish initial guesses for most new variables introduced in terms of a prescribed set of only a few variables, one to determine scale factors for the variables, etc: Each routine is quite simple to understand and wite (but each is necessary for robust simulation results). 
With OSCAR, his new model can be run by itself as a "plant" simulation and can therefore be tested by itself. Because of the particular structure of OSCAR, he finds he can run his new model in several modes a simulation mode whereby the equipment sizes are specified and their operation studied as we 11 as a design mode whereby certain steady state operating levels can be prescribed and the equipment sizes calculated. Any reasonable ad hoc mixture of the two is also possible. He tests his single module by itself until he feels it operates as desired. The RERUN c=pability particularly aids because with a single run, he can study several different operating conditions and alternative specifications.

With his confidence level running reasonably high, he is told by his supervisor not to jump straight into a complete plant simulation, a thing he himself was about to do. He is asked instead to run several old simulations of smaller plants but with his new valve model included. He discovers a few modifications are still needed. After making and testIng them, he now is quite confident of his model.

OSCAR permits. him to build only part of his overall plant model and to test 1t, which he does. Only the simplest of physical properties are used (constants) and so forth. Results are saved. With each success the plant model complexity is increased by adding more structure. If certain precautions are taken, he can use the successful results of earlier runs to initialize each subsequent one, even as he adds more complexity to his model. Continuing in this stepwise manner, he constructs his final model and obtains results fairly quickly. He tends to trust these results because he has understood and tested each step as he took it to get the complete mode1. Alternative control structures replace those used initially to assess their potential, etc." 
The scenario just presented is not to extoll the virtues of simulation but rather to show several of the design features we are including In OSCAR to make it a useful tool for a design engineer. Hopefully it will help to clarify why the system design is proceeding as we report in the next sections.

\subsection{Report Contents}

The report is broken up into the following sections. First we shall present the design goals for OSCAR in Section 2 . Then in Section 3 we shall present details about the initlal plant equipment models which are to be included. These models have two features: relative simplicity but with enough complexity to permit adequate simulation over a wide range of operating conditions. The most significant new work on modeling is for evaporators and condensers, and these results are given in detail. One unit model is not yet included, the turbine model. We have a model available but are not at liberty yet to publish it. If we fail to get the requisite permission to publish the model, we shall have to develop another model by ourselves.

After presenting the models in some detail, we shall then present, in Section 4, the design details established to date for OSCAR. These detalls will show the expected structure of OSCAR and indicate what each part 1s to do. The design is not yet frozen. The approach represents the next generation of several earlier and existing efforts at designing and implementing simulation systems. As such it has features which generalize many features of earlier designs to make the system easier to implement and use while still giving greater flexibility in use.

Finally, the appendix presents the more detailed aspects of the evaporator and condenser modeling. 


\title{
2. Functional Specifications for OSCAR-1
}

OSCAR-1 (OTEC Steady-state and Control System Analysis Routines) is a programing system being developed to permit the steady-state and dynamic simulation of an arbitrarily configured OTEC power system plant. The models which will be included in the current version of OSCAR are listed in Table 2.

\author{
1. Simple Stream Splitter \\ 2. Mixer Unit \\ 3. Valve \\ 4. Pump \\ 5. Pipe \\ 6. Turbine \\ 7. Evaporator \\ 8. Condenser \\ 9. Comventional PI Controllers \\ 10. Other Controllers - not designed yet
}

Table 2 .

Two typical flowsheets which one could simulate are shown in Figures 1 and 2. To perform a dynamic simulation requires two steps: (1) establishing the initial plant state and (2) integrating the dynamic equations forward in time to establish the dynamic behavior. Thus OSCAR wIll comprise two major subsystems - the steady-state analysis subsystem and the dynamic analysis subsystem, with the results of the first being the required initial state for the second. Figure 3 illustrates. 


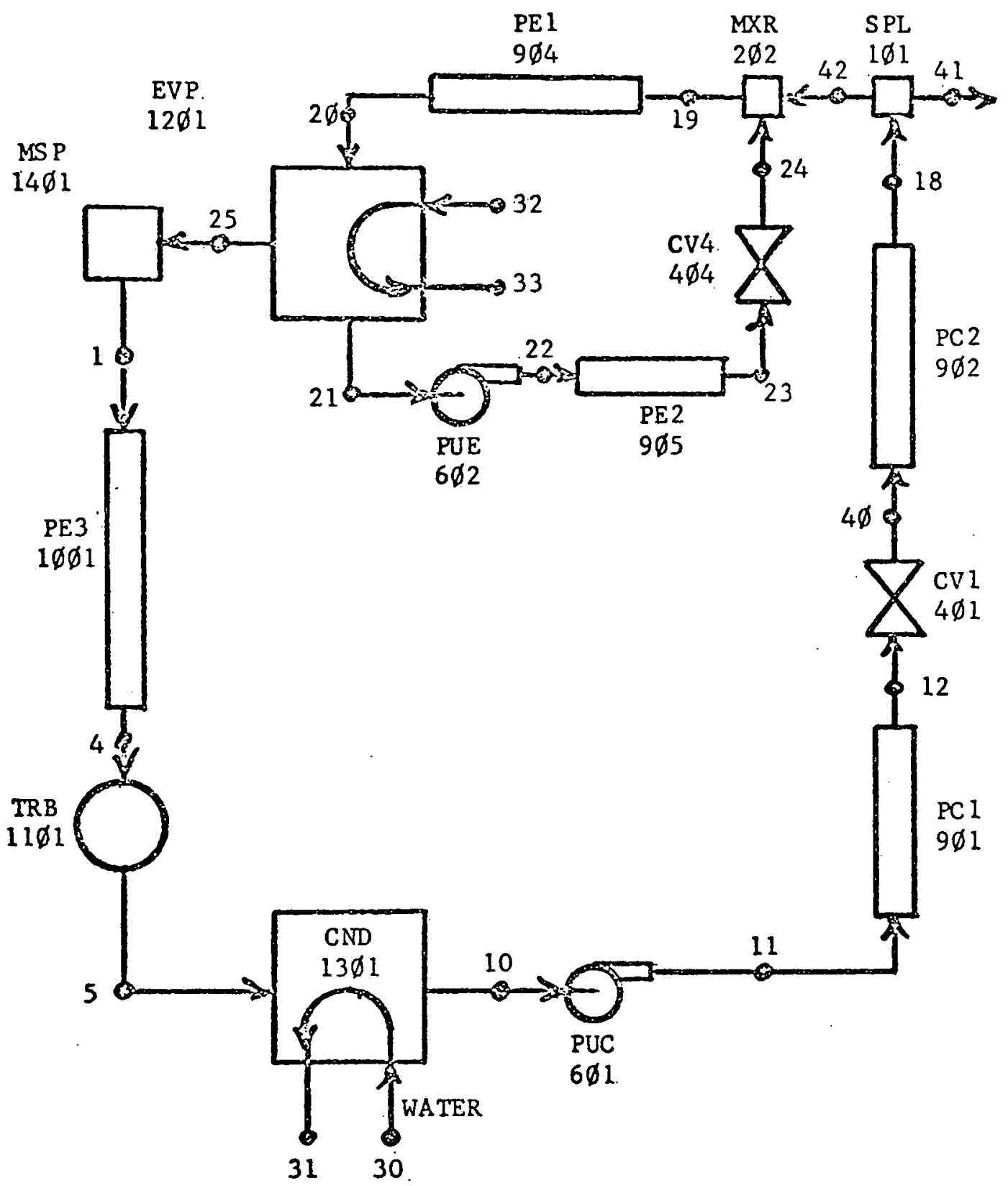

FIGURE 1. OTEC Plant, Variation 1 


$$
-8-
$$

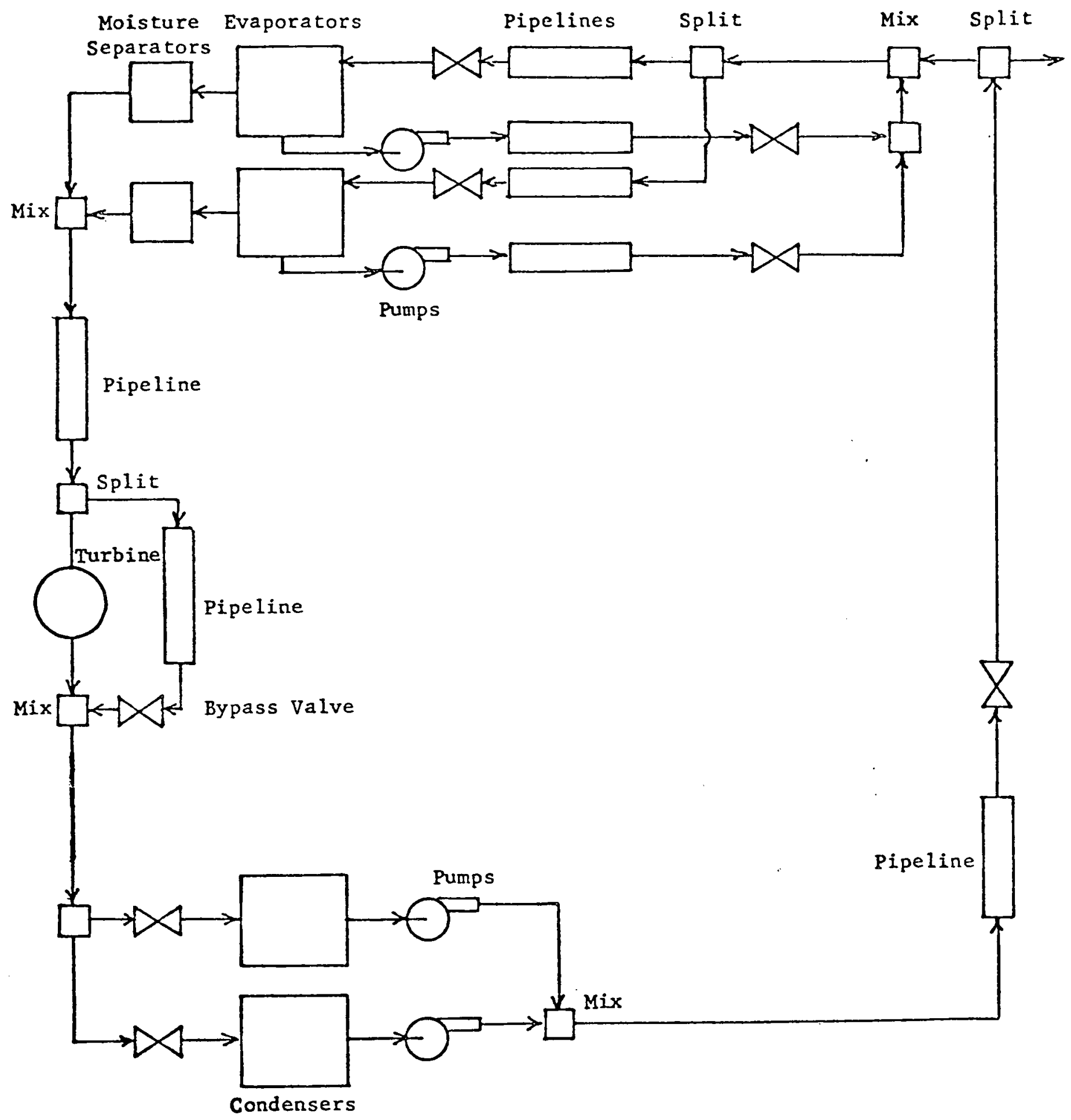

FIGURE 2. OTEC Plant, Variation 2 


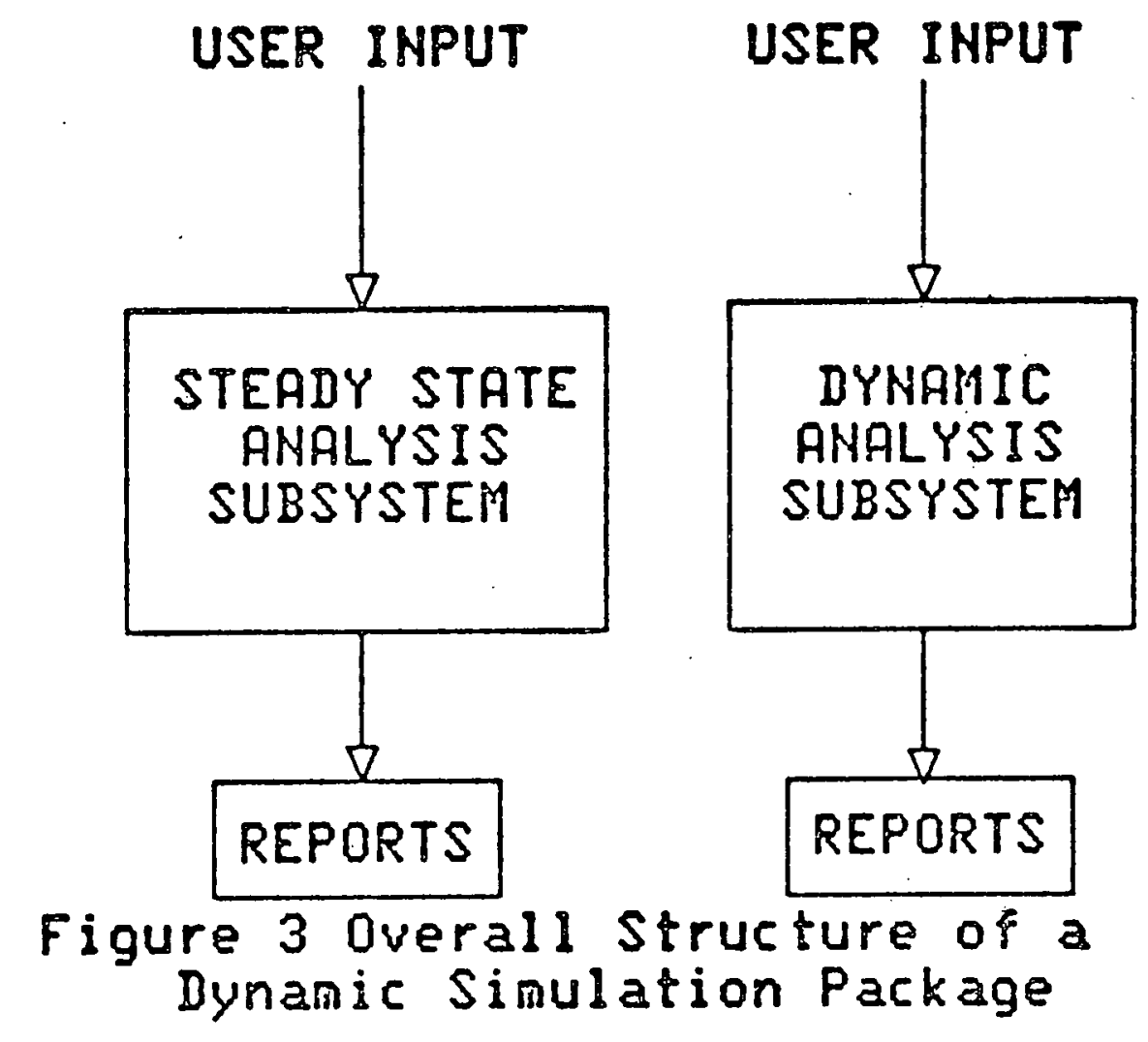


The overall functional specifications for OSCAR-1 are as follows.

1. Modular programing structure.

2. All coding done using "structured programing" concepts.

3. User input will be simple, with the more complicated options defaulted unless he chooses to override them.

4. Very arbitrary user specifications possible. The same models will serve to do simulation as well as design calculations.

5. User can readily add a new unit mode1.

6. Computation results can be saved and continued in a future simulation run.

7. The results of a previous simulation can be used in a subsequent one even if the user adds structure to his plant configuration.

8. All fluid physical properties will be built into the system In a manner that they can readily be changed.

9. The steady-state subsystem will operate by itself and serve to calculate easily and quickly off-design steady-state plant operation.

10. Results from a dynamic Iun will provide initial results for a subsequent steady-state simulation (we do not see yet how to do this one).

11. It w11l be readily possible to add optimization capability to future versions (we do already see how this is done in detail for the steady-state subsystem).

12. Modern stiff integration routines will form the basis of the dynamic subsystem (e.g. EPISODE).

13. The calculation procedure will take full advantage of the sparse nature of the equations used in modeling. It w111 be as efficient as we know how to make it. 


\section{Unit Models for OSCAR-1}

In the modeling which follows, the variable "naming" scheme is intentionally obvious where possible. The units expressed are SI units which may horrify many practicing engineers. It is hoped that the remarkable simplicity in dealing with these units will outweigh the disadvantage of using them here. Simple conversions exist to translate to any system of units desired, and obviously these can be applied to user input and output rather than being used internally.

\subsection{Simple Stream Splitter}

A simple stream splitter (see Figure 4) permits one to split an input stream into two outlet streams having the same temperature, pressure and composition as the feed. The modeling equations are all algebraic and are as follows.

$$
\begin{aligned}
& \text { 1) } \text { FOUT1 + FOUT2 }- \text { FIN }=\varnothing \\
& \text { 2) FOUT1 - S*FIN }=\varnothing \text { (defines } S \text { ) } \\
& \text { 3) } \operatorname{TOUT1} \text { - TTN =6 } \\
& \text { 4) } \operatorname{TOUT2}-\operatorname{TIN}=6 \\
& \text { 5) POUTI - TIN = } 6
\end{aligned}
$$

where FXXX Flow rates, $\mathrm{kg} / \mathrm{s}$

IXXX Temperature, $\mathrm{K}$

$\operatorname{PXXX}$ Pressure, $\mathrm{N} / \mathrm{m}^{2}\left(=\left(\mathrm{kg} \mathrm{m} / \mathrm{s}^{2}\right) / \mathrm{m}^{2}\right)$

S Fraction of inlet stream leaving in outlet stream I

(Note FIN, FOUT1, FOUT2 are obviously flow rates therefore.) 


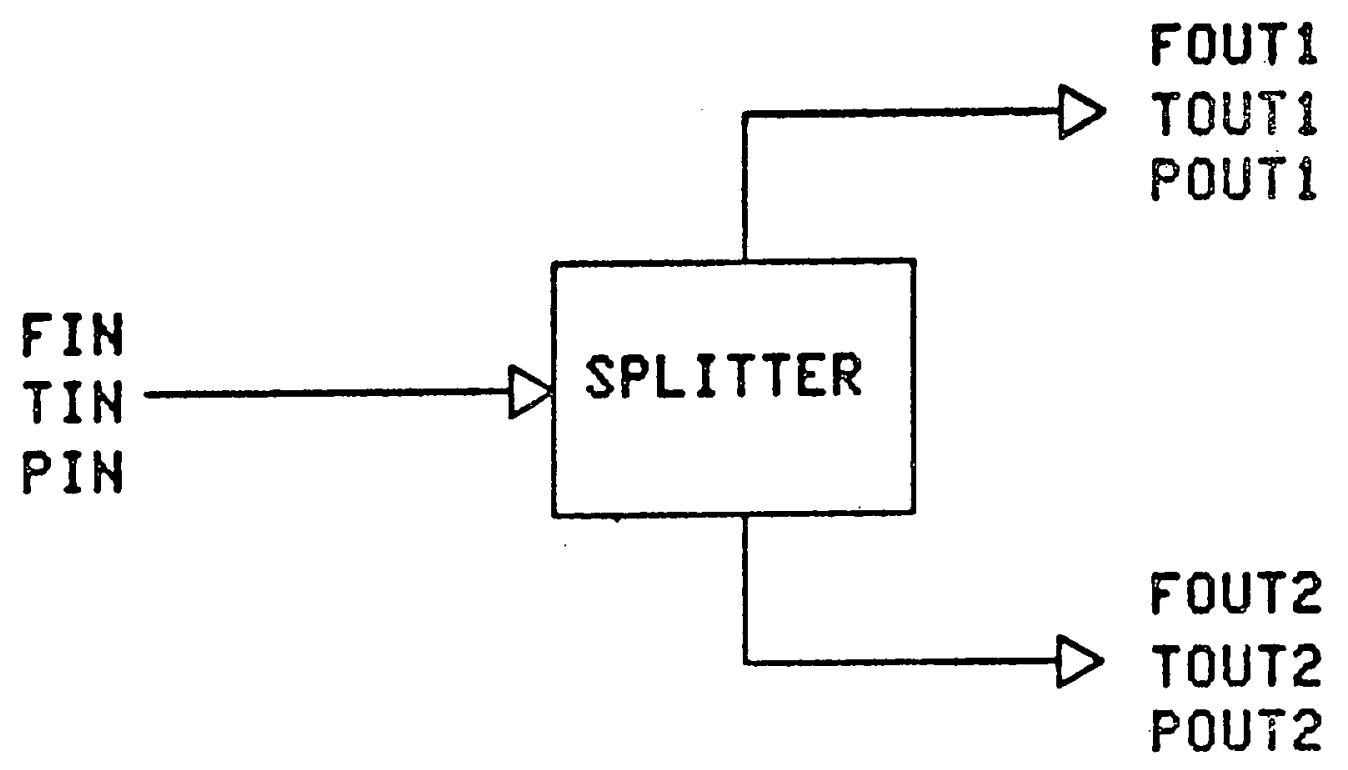

Figure 4 a Simple Stream Splitter Unit 


\subsection{Stream Mixer Unit}

A stream mixer unft is for mixing two inlet streams together to produce a single total outlet stream. It has no capacitance so its model is purely algebraic. The equations are obvious and are as follows (see Figure 5).

$$
\begin{aligned}
& \text { 1) FOUT - FIN1-FIN2 = } \\
& \text { 2) } \operatorname{TOUT*}(F I N 1 * C P 1+F I N 2 * C P 2) \\
& \text { - FIN } 1 * C P 1 * T I N 1 \\
& \text { - } F \text { DN } 2 * C P 2 * \operatorname{TIN} 2=\varnothing \\
& \text { 3). POUT - PIN1 = } \\
& \text { 4) POUT - PIN2 = }
\end{aligned}
$$

where CPX Heat capacity, J/kg K

FXXX Flow rate, $\mathrm{kg} / \mathrm{s}$

$\operatorname{TxXX}$ Temperature, $\mathrm{K}$

PXXX Pressure, $\mathrm{N} / \mathrm{m}^{2}\left(=\left(\mathrm{kg} \mathrm{m} / \mathrm{s}^{2}\right) / \mathrm{m}^{2}\right)$

\subsection{Valve}

A valve unit models a valve. See Figure 6 . The model used here gives rise only to algebraic equations which are as follows.

Material Balance

$$
\text { FOUT }- \text { FIN }=\varnothing
$$

Energy Balance (Kept very simple at present)

$$
\text { TOUT }- \text { TIN }=\varnothing
$$

Pressure Balance

$$
\begin{gathered}
2 * \mathrm{CV}^{2} * \mathrm{DP}-\mathrm{DEN} * \mathrm{FIN}^{2} * \mathrm{AREA}^{2}=\varnothing \\
\mathrm{POUT}+\mathrm{DP}-\mathrm{PIN}=\varnothing
\end{gathered}
$$




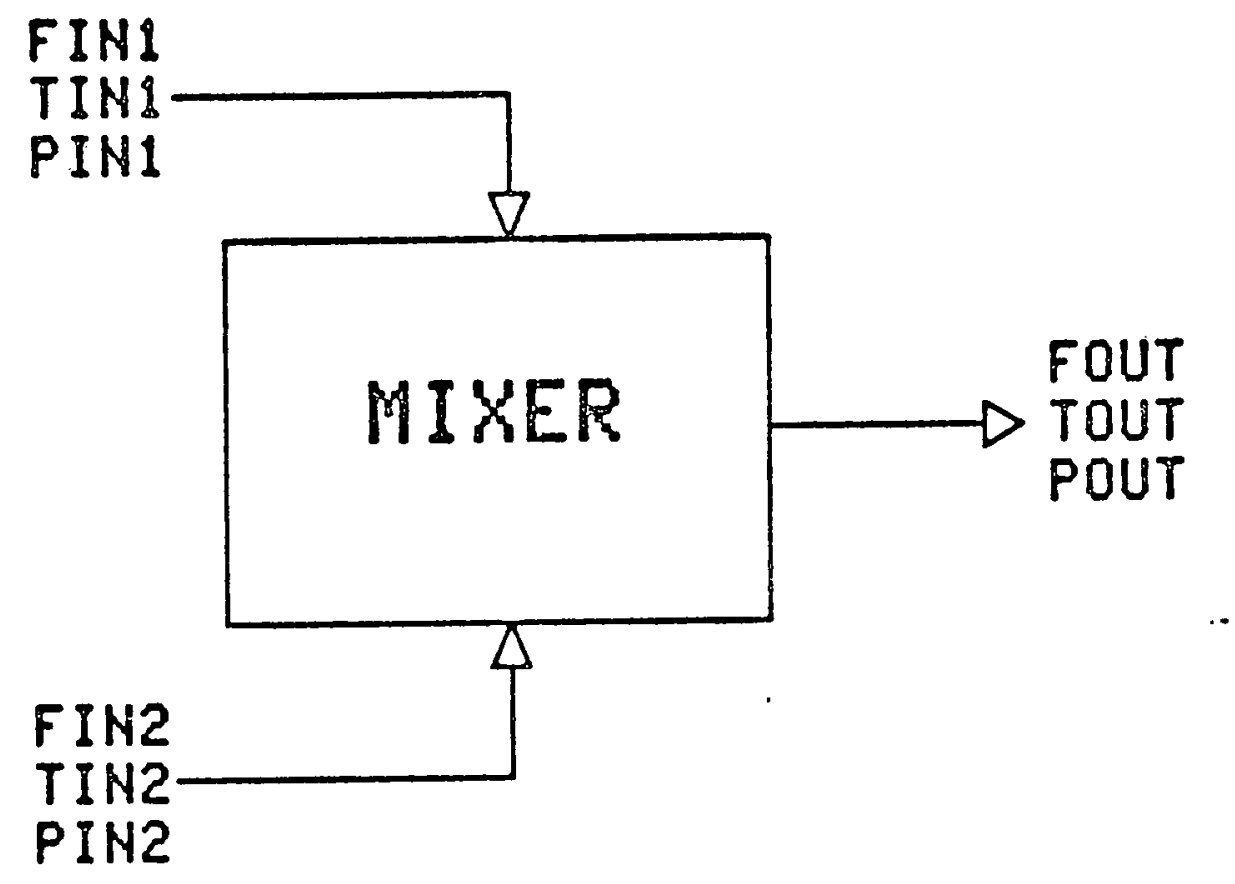

Figure 5 Stream Mixer Unit 


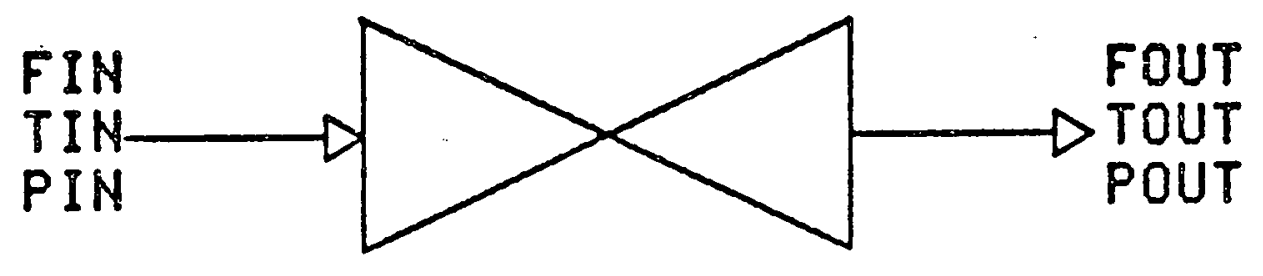

FIGURE 6 A YALYE UNIT 
$-16$.

where CV Valve coefficient, $\sqrt{m}$

DP Pressure drop, $\mathrm{N} / \mathrm{m}^{2}\left(=\left(\mathrm{kg} \mathrm{m} / \mathrm{s}^{2}\right) / \mathrm{m}^{2}\right)$

AREA Valve throat area, $\mathrm{m}^{2}$

DEN Fluid density, $\mathrm{kg} / \mathrm{m}^{3}$

FXXX Flow rate of fluid, $\mathrm{kg} / \mathrm{s}$

IXXX Temperature, $\mathrm{K}$

$\operatorname{PXxX}$ Pressure, $\mathrm{N} / \mathrm{m}^{2}$

3.4 Pump

A pump unit is to model a pump. Figure 7 illustrates a pump unit.

The modeling equations are as follows.

Material Balance

$$
\text { FIN }- \text { FOOT }=\varnothing
$$

Mechanical Energy Balance

$$
\mathrm{DEN} * \mathrm{EFF} * \text { WORK }-\mathrm{DP}=\varnothing
$$

Pump Characteristic Curve

$$
A+B * F I N+C * F I N^{2}-D P=\varnothing
$$

Pump Power

$$
\text { WORK*FIN }- \text { POW }=\varnothing
$$

Energy Balance

$$
\text { WORK }-\mathrm{CP} * \mathrm{DT}=\varnothing
$$

Pressure and Temperature Changes

$$
\begin{aligned}
& \text { POUT - (PIN + DP }=6 \\
& \text { TOUT - TIN + DP })=6
\end{aligned}
$$




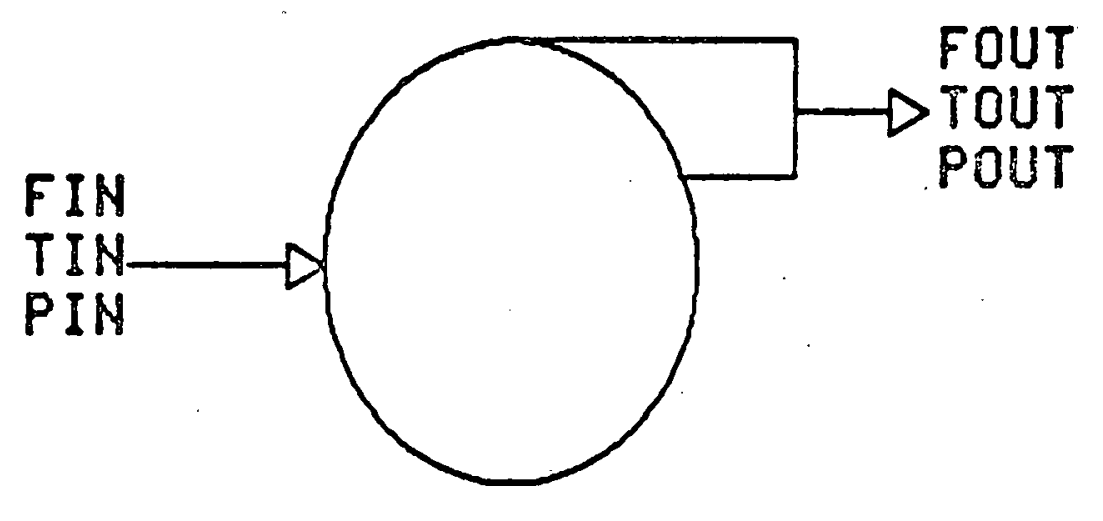

Figure 7 A Puap Unit 
where DEN Fluid density, $\mathrm{kg} / \mathrm{m}^{3}$

EFF Purp mechanical efficiency, dimensionless

POW Power produced by pump, $W$

$$
\begin{aligned}
( & =\mathrm{J} / \mathrm{s}=\mathrm{Nm} / \mathrm{s} \\
& \left.=\left(\mathrm{kg} \mathrm{m} / \mathrm{s}^{2}\right) \mathrm{m} / \mathrm{s}\right)
\end{aligned}
$$

DP Pressure drop, $\mathrm{N} / \mathrm{m}^{2}$

$$
\left(=\left(\mathrm{kg} \mathrm{m} / \mathrm{s}^{2}\right) / \mathrm{m}^{2}\right)
$$

A,B,C Coefficients to a pump curve.

$$
\begin{array}{ll}
\text { A } & \mathrm{N} / \mathrm{m}^{2} \\
\text { B } & \left(\mathrm{N} / \mathrm{m}^{2}\right) /(\mathrm{kg} / \mathrm{s}) \\
\text { C } & \mathrm{N} / \mathrm{m}^{2} /(\mathrm{kg} / \mathrm{s})^{2}
\end{array}
$$

WORK Work supplied by pump drive motor to pump, J

$$
\left(=\mathrm{Nm}=\left(\mathrm{kg} \mathrm{m} / \mathrm{s}^{2}\right) \mathrm{m}\right)
$$

CP Heat capacity, J/kg K

FXXX Fluid flowrate, $\mathrm{kg} / \mathrm{s}, \ldots$

TXXX Temperature, $\mathrm{K}$

$\operatorname{PXXX}$ Pressure, $\mathrm{N} / \mathrm{m}^{2}\left(=\left(\mathrm{kg} \mathrm{m} / \mathrm{s}^{2}\right) / \mathrm{m}^{2}\right)$

\subsection{Pipe}

A pipe unit models a length of pipe. Figure 8 illustrates a pipe unit.

Material Balance (No accumulation)

$$
\text { FOUT }- \text { FIN }=0
$$

Temperature Equations

$$
\begin{aligned}
& \operatorname{TOUT}(t)=\operatorname{TIN}(t-\tau) \\
& \int_{t-T}^{t} \operatorname{FIN}(\theta) d \theta-\operatorname{CAP}=\phi \\
& \operatorname{CAP}-\operatorname{DEN} * \operatorname{LEN} * \operatorname{AREA}=\varnothing \\
& \text { AREA }-\pi * \operatorname{DIA}^{2} / 4=\varnothing
\end{aligned}
$$


$-19-$
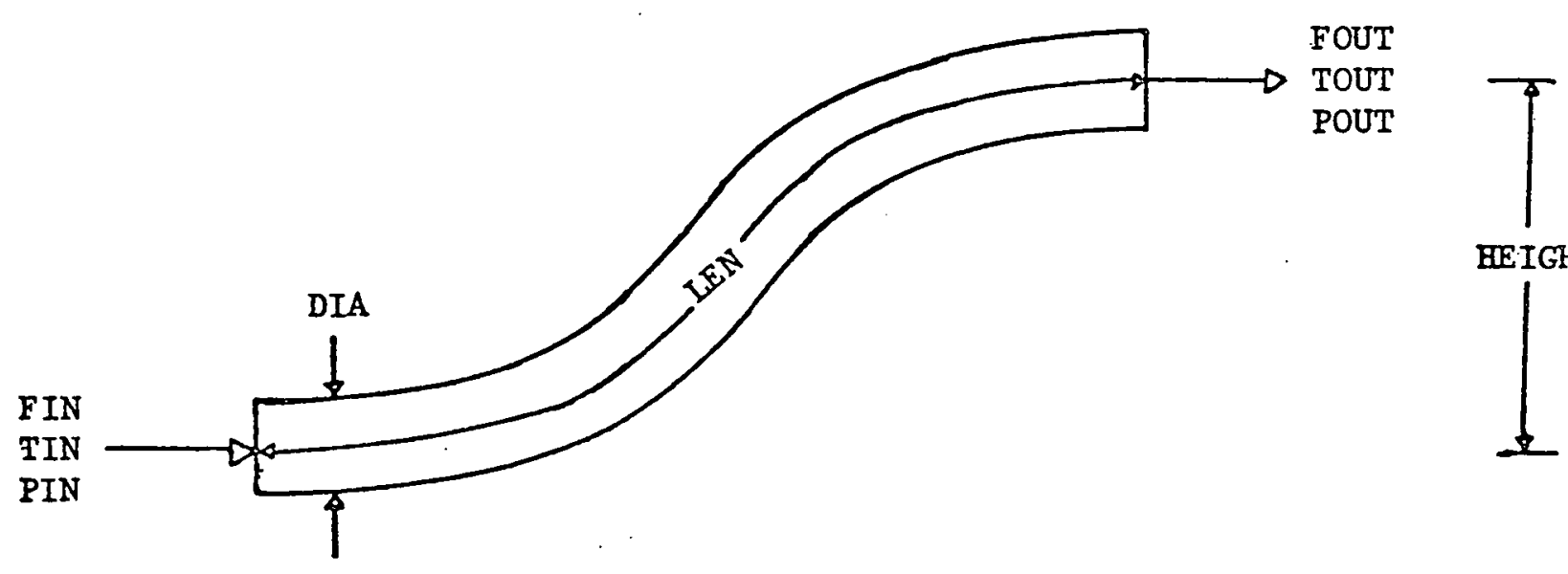

EEIGHT

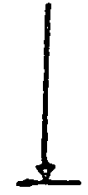

FIGURE 8. Pipe Unit 
Mechanical Energy Balance (Pressure Drop)

$$
\begin{aligned}
&(\mathrm{DP} / \mathrm{DEN})-(4 * \mathrm{FF} * \mathrm{LEN} / \mathrm{DIA}+\mathrm{KEQL}) * \mathrm{VEL}{ }^{2} / 2 \\
&-\mathrm{HEIGHT} * \mathrm{GRAV}=\varnothing \\
& \mathrm{DEN} * \mathrm{VEL} * \mathrm{AREA}-\mathrm{FIN}=\varnothing \\
& \mathrm{REN} * \mathrm{VIS}-\mathrm{DIA} * \mathrm{VEL} * \mathrm{DEN}=\varnothing
\end{aligned}
$$

For laminar flow

$$
F R F * R E N-16=\varnothing
$$

For turbulent flow

$$
\text { FRF }-\phi .125 * R E N^{-0.32}-\phi, \phi \phi 14=\phi
$$

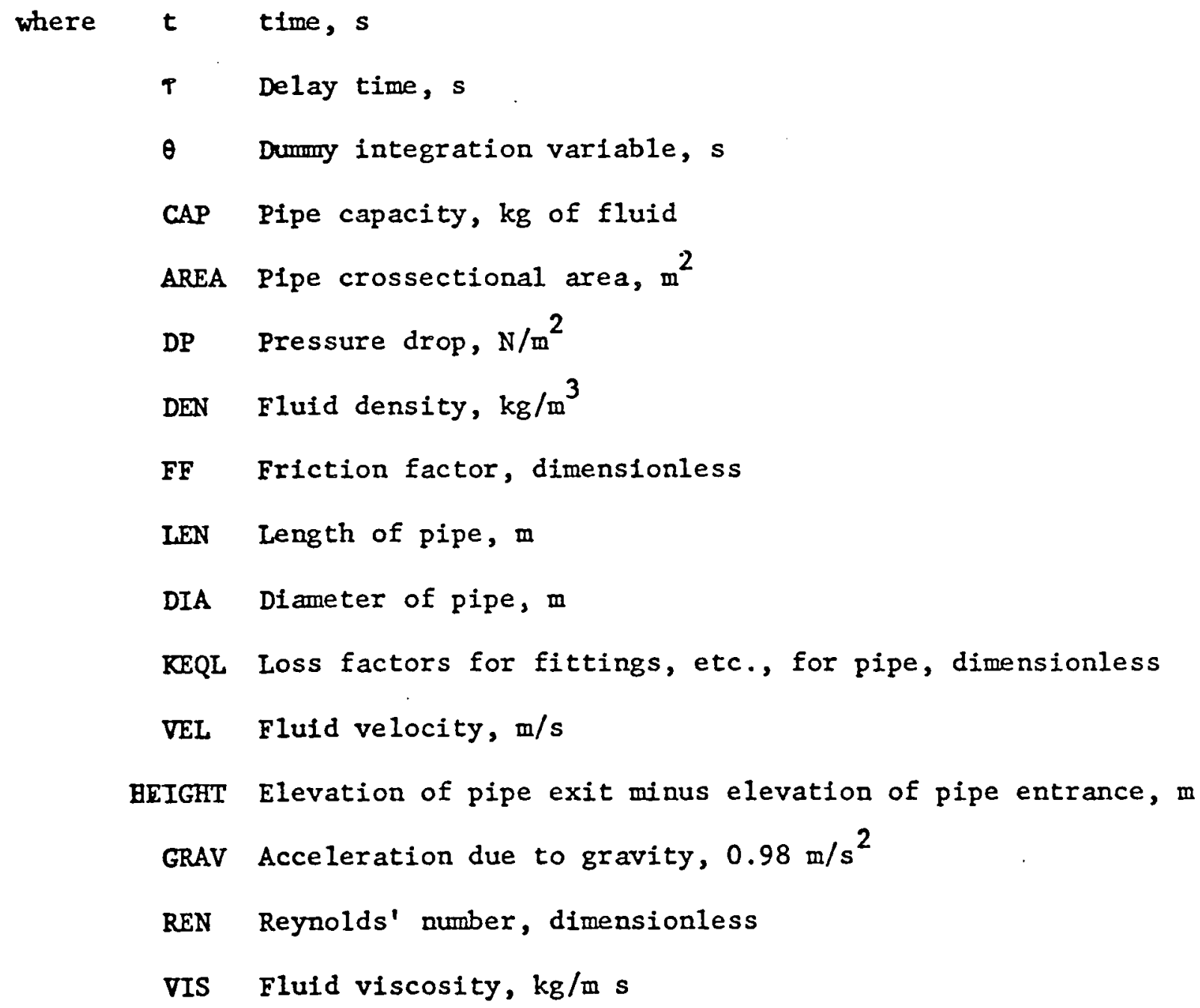




$$
\begin{array}{ll}
\text { FIN, FOUT } & \text { Fluid flowrate, } \mathrm{kg}, \mathrm{s} \\
\text { TIN, TOUT } & \text { Temperature, } \mathrm{K} \\
\text { PIN, POUT } & \text { Pressure, } \mathrm{N} / \mathrm{m}^{2}
\end{array}
$$

\subsection{Turbine}

We cannot publish a turbine model as yet. 


\subsection{Evaporators and Condensers}

\subsubsection{Nomenclature}

The following nomenclature will be used in this section.

C constant

D tube diameter

g gravity

h heat transfer coefficient

$\mathbf{h}_{\mathrm{fg}}$ latent heat of vaporization

k thermal conductivity

$L_{j}$ length of the section $j$ of vertical tube

$M_{j}$ total mass of liquid in the subsystem $j$

in mass flow rate per unit length

n constant

$N_{j}$ number of horizontal tubes in subsystem $\mathbf{j}$

q wall heat flux

$R$ tube radius

$t$ time

$T_{w}$ wall temperature

$T_{v}$ vapor temperature

u velocity of liquid along the tube

o mean velocity

v velocity normal to tube

x coordinate, along the tube

y coordinate, normal to the tube 
$-23-$

Greek Symbols

$\alpha$ thermal diffusivity

$\Gamma_{0}$ volume flow rate per unit length, one side of horizontal tube 8 film thickness

$\Delta \quad$ half film thickness between tubes, or calibration parameter

H viscosity

u kinematic viscosity

Pe liquid density 


\section{7 .2 Introduction}

The evaporator in an OTEC system generates vapor from a flowing liquid film on horizontal or vertical tubes. The vapor at a later point condenses in the condenser on horizontal or vertical tubes. The comon behavior among these components is that the major transport process happens at the liquid films. Following this viewpoint, it becomes possible to simulate the dynamic behaviors of these components by a unified model which models "Thin Film Heat Exchangers" in general.

The design of shell and tube condensers has achieved substantial attention in the past as indicated in the review paper [1]. The thin film evaporators also have been studied extensively in the area of desalination and OTEC applications $[2,3]$. However, appropriate literature are not avai1able for dynamic modeling of these components.

The most primitive approach for the dynamic modeling is to lump all the tubes in the heat exchanger, characterizing them by a single tube. This kind of model has already shown distinct success in a previous dynamic modeling program ODSP [4] which was established by this research group at aMU. However, at some severe transients this model is not able to give correct results due to the nature of the lumped approach winch neglects the time delay aspects of the falling liquid films on the tubes. In order to account for this liquid film time delay, a more realistic model is proposed and will be used in the present investigation.

In a thin film heat exchanger the motion of a liquid film can be Influenced by the motion of the flowing vapor. However, near the central region of the bundle where vapor flow is insignificant the film falls mainly due to gravity. At close to the edge of the bundle the vapor cross flow 
can be strong enough to break the liquid film by shear stresses. The transition of film flow between the shear-controlled and gravity-controlled regimes on horizontal tube bundles can be well described by a dimensionless gas velocity $\mathrm{Jg}^{*}[5]$. In addition, the liquid entraiment and the breakdown of films have been analyzed in [6,7], respectively. In spite of this, the general behavior of this shear dominant film flow is still not well known. On the other hand, the gravity-controlled steady state film flow and heat transfer has been studied extensively in the past $[8,9]$ and the dynamic simulation based upon this flow regime. is more feasible at the present time.

In the present approach, a column of horizontal tubes or a single piece of vertical tube is considered. Liquid film falls vertically due to gravity. The film thickness either increases or decreases dependIng upon whether the unit is a condenser or an evaporator.

The vertical tube will be divided into sections and the horizontal tubes will be grouped. For each section or group of tubes the dynamic behavior is described as a lumped subsystem. With many lumped subsystems arranged in a vertical series the time response of a film is simulated wile keeping calculational effort to a minimum.

In each lumped subsystem the film thickness and the heat transfer coefficients are taken from theoretical studies or empirical correlations. The dynamic behavior of the film is studied with quasi-steady analysis, and some typical results of the model will be compared with detailed exact calculations for the verification of this model. 

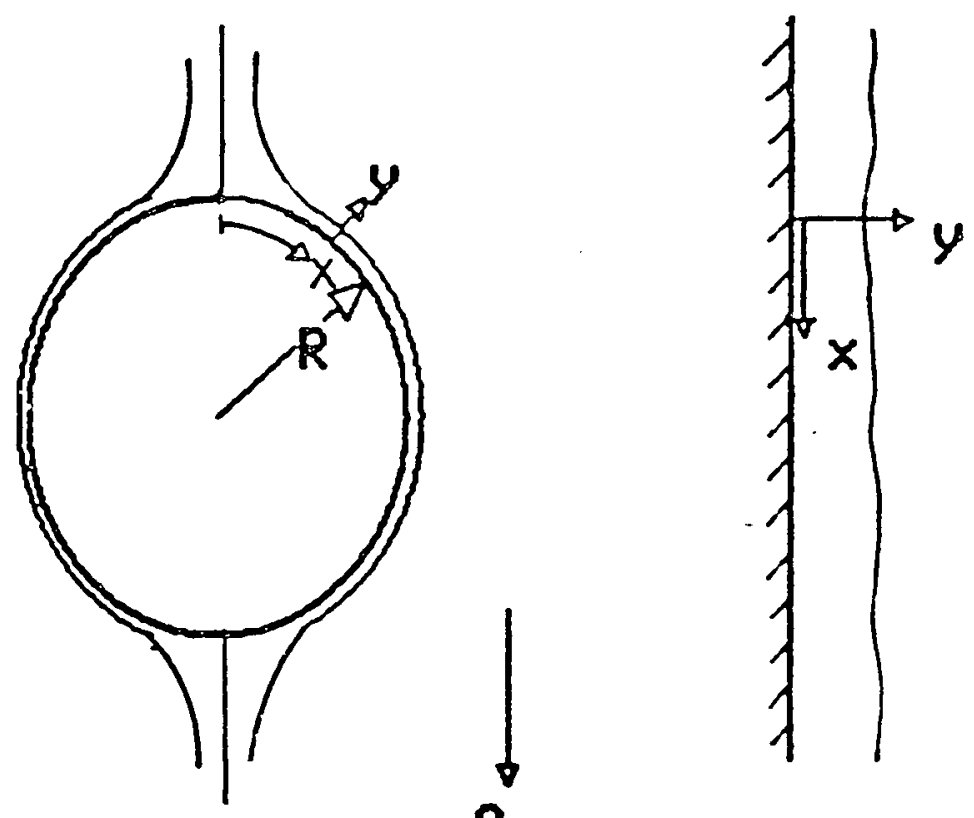

9

(a)

(b)

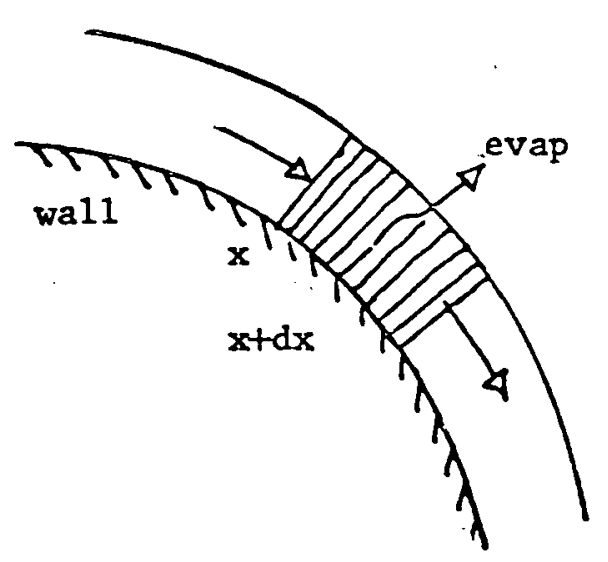

(c)

FIGURE 9. Thin Film Transient Flow Model 


\subsubsection{Fundamental Behaviors of the Jigutd Film}

The dynamic behavior of falling thin films is complicated. There

is neither experimental information nor appropriate analytical results available in the open literature. The lack of physical understanding of the transient phenomena causes the difficulty in dynamic modeling.

For this reason, an accurate analytical study is performed to reveal the physical behavior of the transients. Following this, a simplified model can be established and its accuracy will be justified from proper comparisons between the results of accurate analysis and the simple model.

\section{A. Horizontal Tubes:}

The liquid film in free fall detaches from a horizontal tube before. it reaches the top of the next tube. The flowing distance on each tube is always short so that the film is generally in laminar regime. Occasionally waves develop on the film. When boiling occurs on the surface, small bubbles may exist in the film. The complications of the film flow due to these phenomena are neglected in the present analysis which is considered as a first approach to the dynamic simulation. It is also assumed that the complete film behavior can be described by two-dimensional boundary layer analysis. The entrance effect due to the slightly subcooled feeding liquid is insignificant, also the liquid falling between tubes as a smooth film.

The transient laminar flow and heat transfer behavior of thin fIlms on a tube can be analyzed with the boundary layer approach. The coordinate systems are illustrated in Figure $9(\mathrm{a}),(\mathrm{b})$. The transient momentum equation for a horizontal tube is in the form of 


$$
\frac{\partial u}{\partial t}+u \frac{\partial u}{\partial x}+v \frac{\partial u}{\partial y}=g \sin \frac{x}{R}+u^{2} \frac{\partial^{2} u}{\partial y^{2}}
$$

The same equation can be used for vertical tubes with $\sin x / R \equiv 1$. With a quasi-steady approach [10] and considering the small thickness of the film, the above equation can be reduced to

$$
g \sin \frac{x}{R}+u^{2} \frac{\partial^{2} u}{\partial y^{2}}=0
$$

with boundary conditions

$$
\begin{array}{ll}
u=0 & \text { at } y=0 \\
\frac{\partial u}{\partial y}=0 & \text { at } y=6
\end{array}
$$

Finally, the solution for velocity profile is

$$
\mathrm{u}=-\frac{\mathrm{g}}{\mathrm{u}} \sin \left(\frac{\mathrm{x}}{\mathrm{R}}\right)\left[\frac{\mathrm{y}^{2}}{2}-\delta \mathrm{y}\right]
$$

The transient continuity equation for the liquid film can be written In the form of (see Figure 9c)

$$
-\frac{\partial \delta}{\partial t}=\frac{\partial}{\partial x} \int_{0}^{\delta} u d y+\frac{q_{w}}{p_{\ell} h_{f g}}
$$

Inserting (4) into (5) results in a transient continuity equation with quasisteady velocity profile. That is

$$
\frac{\partial b}{\partial t}+\frac{\partial}{\partial x}\left[\frac{g \sin \left(\frac{x}{R}\right)}{3 u} \delta^{3}\right]+\frac{q w}{p_{l} h_{f g}}=0
$$

This is the transient equation for film thickness 8 . After $\delta$ is obtained, the velocity profile can be evaluated from equation (4). 


\section{Transient Solution}

This equation is highly non-linear. Therefore the method of solution is very involved. Some specific cases are studied and presented In the appendix. These exact solutions are used to justify the simpler approximate solutions which were employed in the present model for simulation. A typical result is indicated in Figure 10.

\section{Quasi-steady Solution}

Generally, the quasi-steady approach was used in the present study. The first term in equation (5) will be neglected. Letting the wall heat flux be a constant, the equation can be linearized by considering $8^{3}$ as a new variable. The initial condition of the resulting equation is that the inlet volume flow rate per unit length equals $2 \Gamma_{0}$. Finalis

$$
s=\left\{\left[\left(\frac{3 U \Gamma_{0}}{g}\right)-\left(\frac{q_{w}}{\rho_{l} f_{g}}\right)\left(\frac{3 U R}{g}\right)\left(\frac{x}{R}\right)\right] / \sin \left(\frac{x}{R}\right)\right\}^{1 / 3}
$$

As mentioned before, $\sin \left(\frac{x}{R}\right) \equiv 1$ for vertical tubes. In most cases the rate of evaporation of the liquid on an horizontal tube is very much less than the liquid flow rate; thus, $q_{w}$ can be set to zero in the above equation without making any observable error [11].

In many cases the tubes are coated with heat transfer augmentation material such that boiling occurs in the evaporator. The heat transfer coefficient of the boiling thin film can be put in a general form [12]

$$
h=C\left(T_{w}-T_{v}\right)^{n}
$$



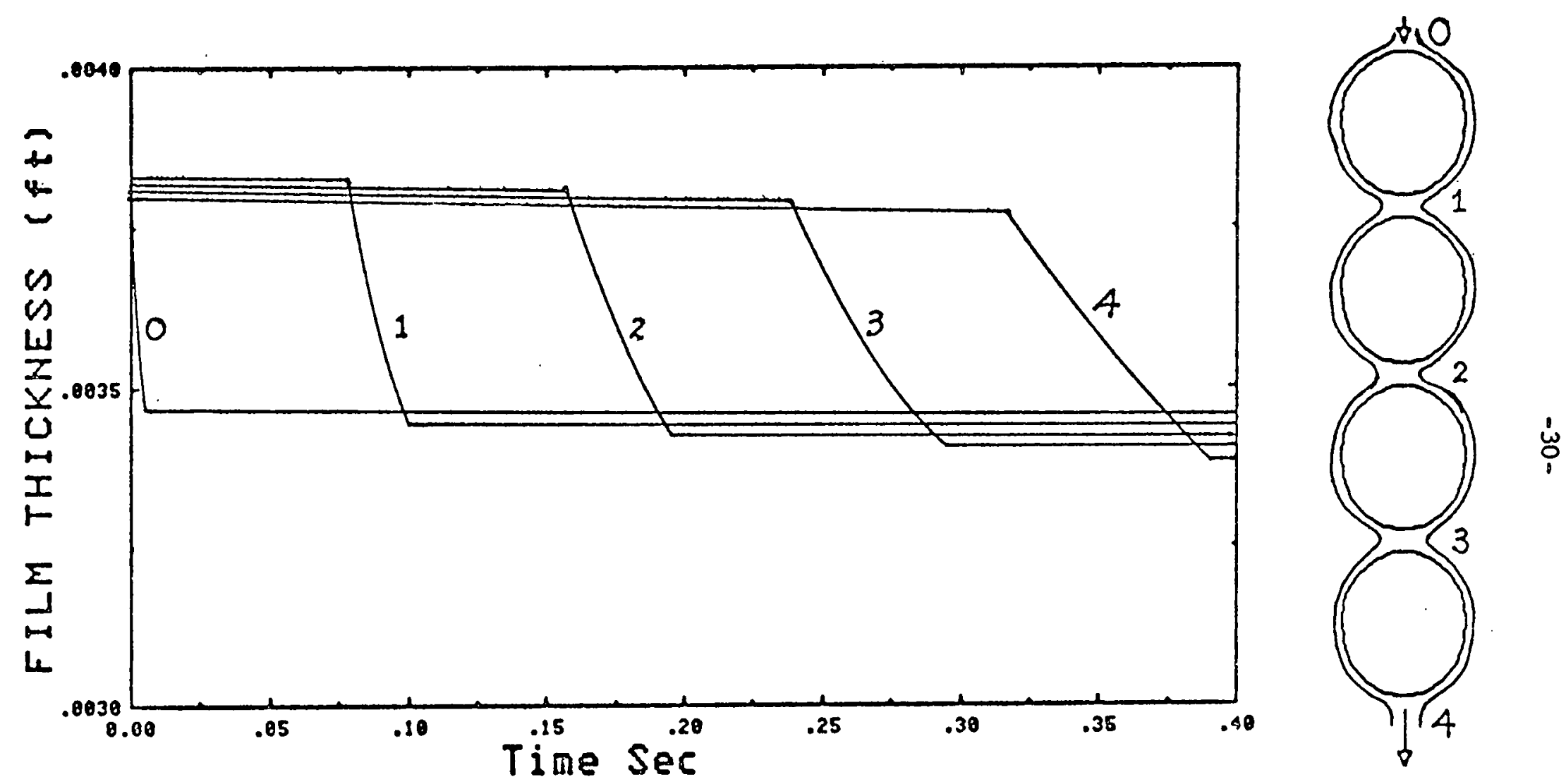

Figure 10 Evaporating $\mathrm{NH}_{3} \mathrm{Film}$ on 1 in 0.0 . Tube 
In a condenser or when pure evaporation occurs the heat transfer coefficient is related to the film thickness as [13]

$$
h=k / 8
$$

B. Vertical Tubes:

Liquid falling on a vertical tube may be either in wavy laminar flow or in turbulent flow. Correlations are presented here for smooth tubes and the equivalent equations will be used for fluted tubes when available. The film thickress is described as [14]

$$
8 /\left(\frac{u^{2}}{8}\right)^{1 / 3}=0.36\left(\frac{v 8}{v}\right)^{0.55}
$$

The heat transfer coefficient for wavy laminar flow is

$$
h=0.606\left(k^{3} g / u^{2}\right)^{1 / 3}[\Gamma / \mu]^{-0.22}
$$

and

$$
\mathrm{h}=3.8 \times 10^{-3}\left(\mathrm{k}^{3} \mathrm{~g} / \mathrm{u}^{2}\right)^{1 / 3}(4 \Gamma / \mu)^{0.4}\left(\frac{u}{\alpha}\right)^{0.65}
$$

for turbulent flow with laminar to turbulent transition [8] at

$$
\frac{4 \Gamma}{\mu}=5800\left(\frac{U}{\alpha}\right)^{-1.06}
$$




\subsubsection{Dynamic Modeling of the Liquid Film}

Lumped subsystems are assigned to several consecutive horizontal tubes or a section of vertical tubes. Within that subsystem, the quasi-steady approach is used. Between subsystems a proper delay time is chosen to take into account the free falling of liquid between horizontal tubes as well as the finite liquid flow velocity along the tube. When the number of horizontal tubes in a subsystem equals the total number of tubes in a column or the length of a vertical section equals the total length of the tube, the present model corresponds to the single lumped model in ODSP. When there is only one horizontal tube in a subsystem or a very short length of vertical section in a subsystem, the present model approaches the exact case. The schematics of the model are shown in Figure 11.

The mass balance of each lumped subsystem $j$ can be written as

$$
\frac{d M_{j}}{d t}=\dot{m}_{i n \cdot j}-\dot{m}_{\text {out } . j}-\dot{m}_{\text {evap } \cdot j}
$$

where $\dot{\mathrm{m}}_{\text {evap.j }}$ is positive for evaporation and negative for condensation. In order to solve this equation, all the $\dot{m}^{\prime} s$ must be present in terms of $\mathrm{M}^{\prime} s$.

In the evaporator, dryout of the liquid film may occur during a transient. This corresponds to the case of $\mathrm{M}_{j}=0$ in that subsystem.

A. Horizontal Tubes:

The flow rate at the inlet of subsystem $j$ comes from subsystem $j-1$.

$$
\dot{\mathrm{m}}_{\text {In } \cdot j}(t)=\dot{\mathrm{m}}_{\text {out } \cdot j-1}\left(t-t_{0}\right)
$$

where $t_{0}$ is the delay time. The total mass in the subsystem is 

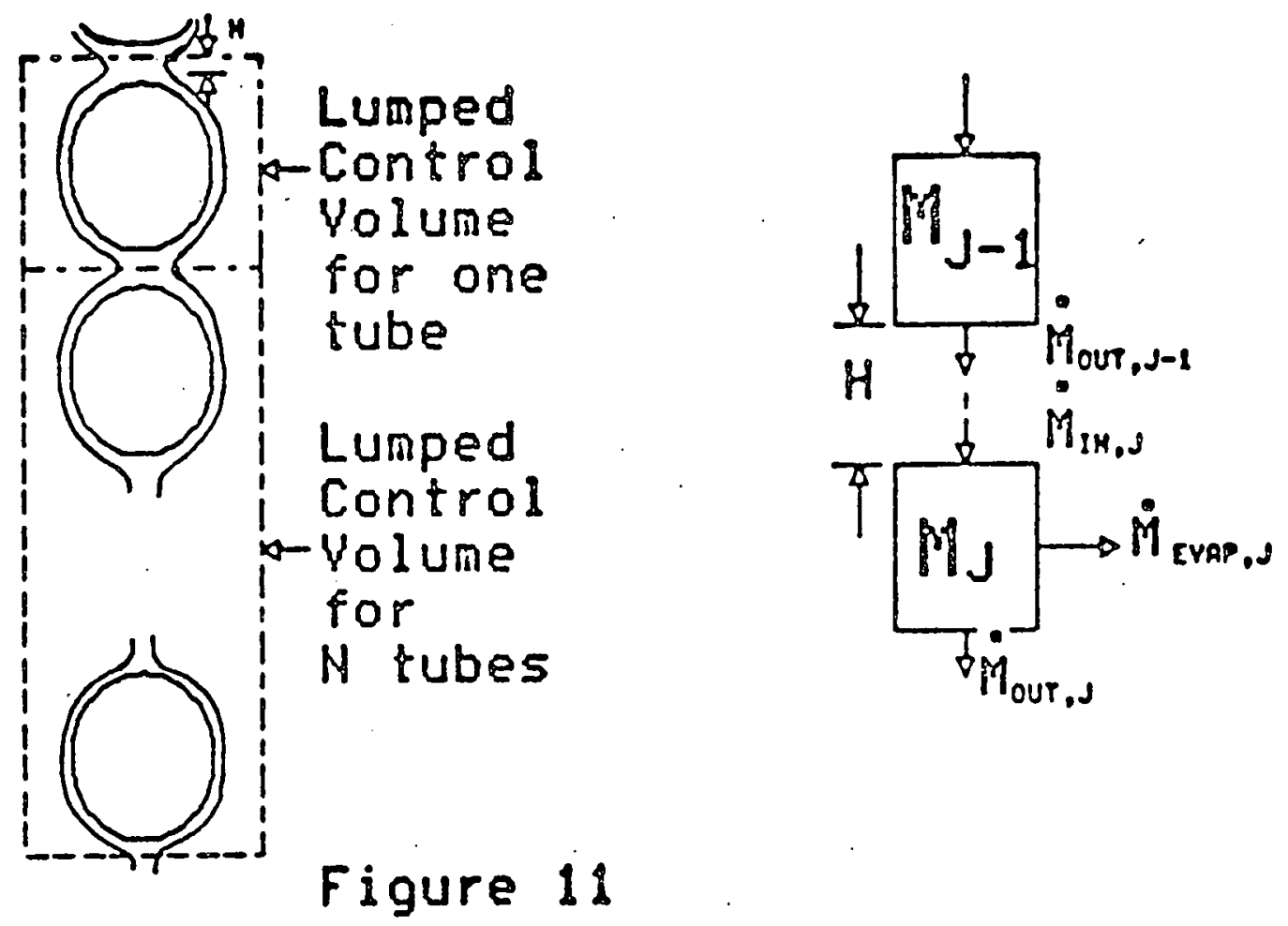


$$
M_{j}=N_{j} \rho_{\ell} \int_{0}^{\pi R} \delta(x) d x
$$

Using equation (7) for $\delta(x)$, with $q_{w}=0$, we get

$$
M_{j}=2 N_{j} \ell^{R}\left[\frac{3 u \dot{m}_{\text {out.i }}}{2 p_{\ell^{g}}}\right]^{1 / 3} \int_{\Delta}^{\pi-\Delta} \sin y^{-1 / 3} d y
$$

or

$$
\dot{\mathrm{m}}_{\text {out } \cdot j}=\frac{2 p_{\ell^{g}}}{3 U}\left[\frac{\mathrm{M}_{j}}{2 \mathrm{~N}_{j} \mathrm{P}_{\ell^{R}} \int_{\Delta}^{\pi-\Delta} \sin ^{-1 / 3} y d y}\right]^{3}
$$

The values of the $\Delta$ is assigned to be the half thickness of the falling film between horizontal tubes. It also can be considered as an empirical value evaluated by comparing results obtained here with results using the exact solution in the appendix. The evaporation rate will be

$$
\dot{\mathrm{m}}_{\text {evap } \cdot j}=\overline{\mathrm{h}} \cdot 2 \mathrm{~N}_{j} \pi R\left(\mathrm{~T}_{w}-\mathrm{T}_{v}\right) / \mathrm{h}_{\mathrm{fg}}
$$

$$
\text { where } \bar{h}=\frac{1}{\pi R} \int_{0}^{\pi R} h(x) d x
$$

with $h(x)$ given from equations (8) or (9) and

$$
\text { presented in terms of } \mathrm{M}_{\mathrm{j}} \text {. }
$$

The initial condition of the resulting equation for $M_{j}$ can be deduced from equation (16) at the initial steady state. 


\section{B. Vertical Tubes:}

The same equation (15) can be used for vertical tubes. The total mass in the subsystem is

$$
M_{j}=L_{j} \pi D \delta \rho_{\ell}
$$

Using equation (10) for $\delta$, we get

$$
M_{j}=0.36 L_{j}\left(\pi D p_{\ell}\right)^{0.45}\left(\frac{u^{2}}{g}\right)^{1 / 3}\left(\frac{\dot{m}_{\text {out } . j}}{v}\right)^{0.55}
$$

or

$$
\dot{\mathrm{m}}_{\text {out.j }}=v\left[0.36 \dot{L}_{j}\left(\pi D_{\ell}\right)^{0.45}\left(\frac{v^{2}}{g}\right)^{1 / 3}\right]^{-\frac{1}{0.55}}\left(M_{j}\right)^{\frac{1}{0.55}}
$$

The evaporation rate is then

$$
\dot{\mathrm{m}}_{\text {evap } \cdot j}=\overline{\mathrm{h}} \pi \mathrm{DL}_{\mathrm{j}}-\left(\mathrm{T}_{\mathrm{w}}-\mathrm{T}_{\mathrm{v}}\right) / \mathrm{h}_{\mathrm{fg}}
$$

and $\vec{h}$ is the averaged heat transfer coefficient using $h(x)$ in equations (11) and (12).

\subsubsection{Dynamic Modeling of the Heat Exchangers}

The schematic of the thin film heat exchanger model is shown in Figure 12. All the vapor is considered as one lumped unit. For each subsystem the liquid film, the tube wall, and the water side are modeled, respectively. At the bottom of the exchanger a hot well is considered.

For the purpose of illustration, the equations are written for a model containing three subsystems. The general equations will be stated first, then the particular considerations to distinguish condensers and evaporators will be pointed out later. 


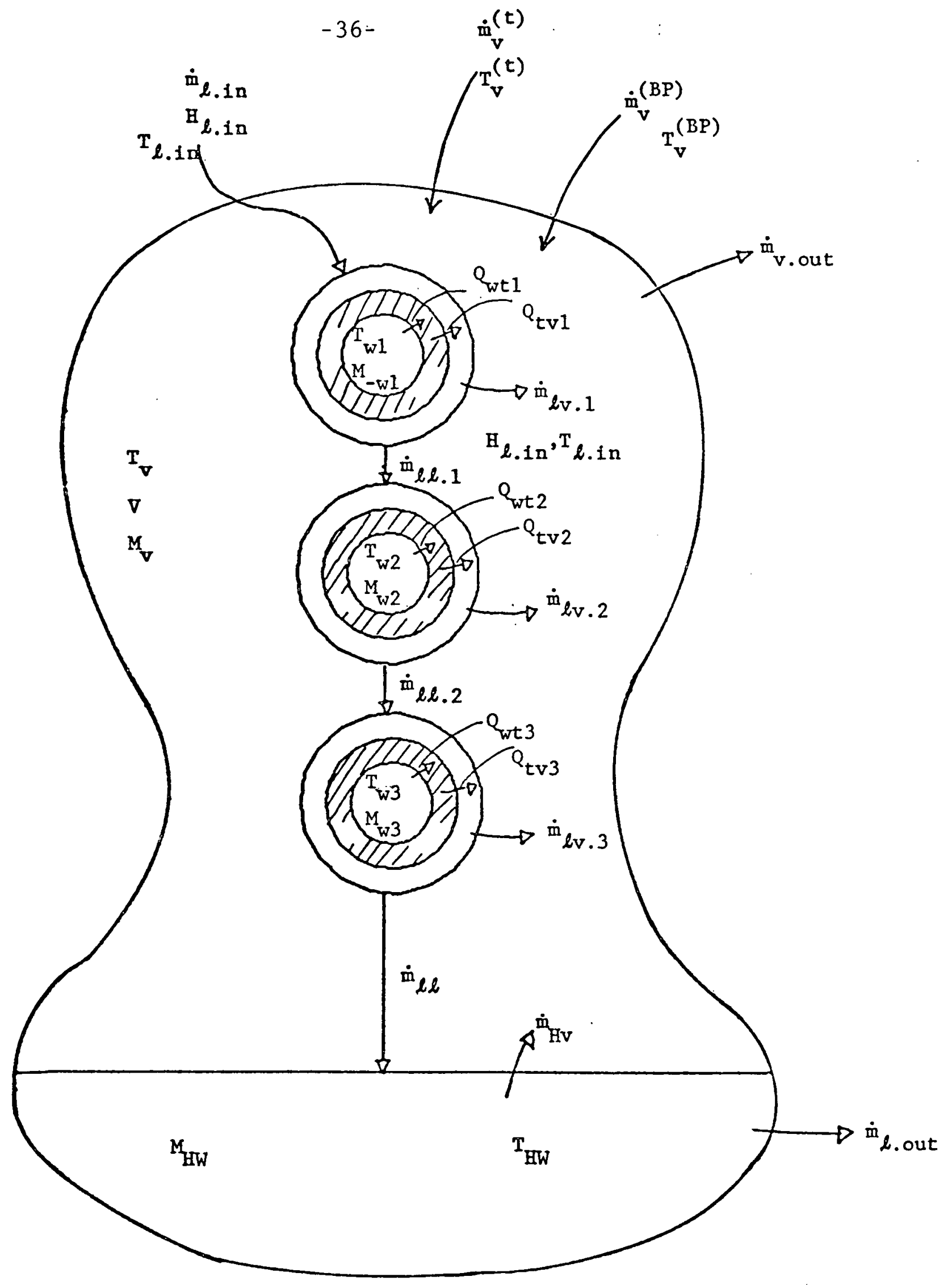

FIGURE 12. Unified Model for Thin Film Heat Exchangers 
$-37-$

A. General Equations

Due to the specific design, the following parameters can be evaluated

$$
\begin{aligned}
& D_{0}=D_{i}+2 \delta \\
& A_{i j}=\pi D_{i} L N_{j}, \quad j=1,2,3 \text { for each subsystem } \\
& A_{o j}=A_{i j} D_{o} / D_{i} \\
& \dot{M}_{t j}=\left[\left(A_{i j}+A_{o j}\right) / 2\right] B p_{t} \\
& M_{w j}=\left(\pi D_{i}^{2} / 4\right) L N_{j} P_{w}
\end{aligned}
$$

Then the transient heat balance of water, tube and ammonia can be formulated. Nomenclature appears in Table 3. 
Table 3. Nomenclature Used in the Derivations of the Exchanger

Nomenclature

A

A

C

$D_{1}$

Do

h

$\mathrm{h}_{\text {wt }}$

$h_{t v}$

H

k

L

$\dot{\mathrm{m}}_{\mathrm{w}}$

$\dot{m}_{v}$

$\dot{\mathrm{m}}_{\ell v}$

$\dot{\mathrm{m}}_{\ell, \text { out }}^{\prime}$

$\dot{\mathrm{m}}_{\ell \ell}$

in

$\underline{M}$

$M_{W}$

$M_{t}$

\section{Interpretation}

Heat transfer area based on $D_{i}$

Heat transfer area based on $D_{0}$

Heat capacity

Inside tube diameter

outside tube diameter

Heat transfer coefficient

Heat transfer coefficient, water to tube

Heat transfer coefficient, tube to anmonia vapor

Enthalpy

Thermal conductivity

Length of tube

Water flow rate

$\mathrm{NH}_{3}$ vapor leaving system

$\mathrm{NH}_{3}$ going from liquid to

$\mathrm{NH}_{3}$ liquid leaving hotwe 11

Excess $\mathrm{NH}_{3}$ liquid leaving evaporator and going to hotwe 11

Mass evaporation rate from hotwe 11 to vapor

Molecular weight

Mass of water in tubes

Mass of metal in tubes
Units

m

m

$\mathrm{J} / \mathrm{kg} \mathrm{K}$

m

m

$\mathrm{J} / \mathrm{s} \mathrm{m}^{2} \mathrm{~K}$

$\mathrm{J} / \mathrm{s} \mathrm{m}^{2} \mathrm{~K}$

$\mathrm{J} / \mathrm{s} \mathrm{m}^{2} \mathrm{~K}$

$\mathrm{J} / \mathrm{kg}$

$\mathrm{J} / \mathrm{s} \mathrm{mK}$

m

$\mathrm{kg} / \mathrm{s}$

$\mathrm{kg} / \mathrm{s}$

$\mathrm{kg} / \mathrm{s}$

$\mathrm{kg} / \mathrm{s}$

$\mathrm{kg} / \mathrm{s}$

$\mathrm{kg} / \mathrm{s}$

$\mathrm{kg} / \mathrm{kg}$ mole

$\mathrm{kg}$

$\mathrm{kg}$ 
Table 3 (contd)

Nomenclature

$M_{\ell}$

$\mathbf{M}_{\mathbf{v}}$

N

$\mathbf{P}$

Pat

Qwt

$Q_{\text {tv }}$

$\mathbf{R}$

$t$

$T_{t}$

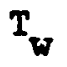

$T_{\text {ev }}$

$\boldsymbol{\nabla}$

2

\section{Interpretation}

Mass of $\mathrm{NH}_{3}$ in liquid on tules

Vapor in evaporator, hotwe11, and moisture separator

Number of tubes

Pressure of vapor $v$ in the vesse

Saturation pressure

Heat transferred from tubes to water

Heat transferred from tubes to ammonia vapor

Gas constant

Time

Average temperature of tube metal

Average temperature of water

Average temperature of both

liquid and vapor $\mathrm{NH}_{3}$ in system

Volume of vapor in evaporator, hotwe 11 and moisture separator

Length, measured from water inlet
Units

$\mathrm{kg}$

$\mathrm{kg}$
$\mathrm{N} / \mathrm{m}^{2}$

$\mathrm{N} / \mathrm{m}^{2}$

$\mathrm{J} / \mathrm{s}$

$\mathrm{J} / \mathrm{s}$

s

R

$\mathbf{K}$

$\mathbb{R}$

$m^{3}$

m

\section{Greek Letters}

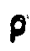

$\mathbf{Y}$

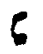

$\lambda$
Density

Transit time

Length constant

Latent heat of vaporization

Tube wall thickness $\mathrm{k} / \mathrm{m}^{3}$

s

m

$\mathrm{J} / \mathrm{kg}$

m 
Table 3 (contd)

Subscripts

j

$\ell$

$\mathbf{w}$

$t$

HW

In

HV

\section{Interpretation}

The subsystem $j$

Liquid $\mathrm{NH}_{3}$

Water

Tube

Hotwe 11

Inlet

Vaporization from hotwe 11 
$-41-$

Heat Balance for Water

$$
M_{w j} C_{w} \frac{d T_{w j}}{d t}=-Q_{w t j}+\dot{m}_{w j} C_{w}\left(T_{w j}(0, t)-T_{w j}\left(L_{e}, t\right)\right)
$$

where $Q_{t w j}$ is the heat transferred from tube to water. In compatible units, it is

$$
Q_{w t j}=h_{t w j} A_{i j}\left(T_{w j}-T_{t j}\right)
$$

The second term at right hand side of the heat balance equation considers the incoming and outgoing enthalpies of water of the condenser tube. The outlet water temperature $\mathrm{T}_{j}\left(\mathrm{~L}_{\mathrm{e}}, t\right)$ is related to the inlet water temperature $T_{w j}(0, t)$ and the vapor temperature $T_{\ell v}(t)$.

This relationship is accomplished by writing the steady state water and tube heat balances. These balances are, respectively:

Water Heat Balance

$$
\left(\frac{\dot{m}_{w j} C_{w}}{\pi D_{i} h_{w t j}}\right) \frac{d T_{w j}(z)}{d z}-T_{w j}(z)+T_{t j}(z)=0
$$

Tube Heat Balance

$$
h_{w t j}\left(T_{w j}(z)-T_{t j}(z)\right)=h_{t v j}\left(T_{t j}(z)-T_{\ell v}\right)
$$

Eliminate $T_{t j}(z)$ to get

$$
\zeta_{j} \frac{d T_{w j}(z)}{d z}+T_{w j}(z)=T_{\ell v}
$$

where $\sigma_{j} \equiv$ length constant $\equiv\left[\frac{1}{h_{w t j}}+\frac{1}{h_{t v j}}\right]\left(\frac{\dot{m}_{w j} C_{w}}{\pi D_{i}}\right)$ 
The solution of this equation evaluated at $z=\mathrm{L}_{e}$ is

$$
T_{w j}\left(L_{e}\right)=T_{w j}(0) e^{-L_{e} / \sigma_{j}}+\left[1-e^{-L_{e} / \sigma_{j}}\right] T_{l v}
$$

This is the outlet water temperature at steady state. To approximate the dynamic behavior, the transit times of water and vapor are intro-. duced as time delays. The transit time of water through the condenser tube from $z=0$ to $z=L_{e}$ is

$$
\gamma_{j}=\frac{M_{w j}}{\dot{m}_{w j}}
$$

The averaged time delay is half of $\gamma_{j}$. As a result, the outlet water temperature can be presented as

$$
T_{w j}\left(L_{e}, t\right)=T_{w j}(0, t-\gamma) e^{-L e^{/ \sigma_{j}}}+\left(1-e^{-L e^{/ \zeta_{j}}}\right) T_{d v}\left(t-\frac{\gamma}{2}\right)
$$

In sumary, the water temperature is

$$
\frac{d T}{d t}=\frac{1}{M_{w j} C_{w}}\left[-Q_{w t j}+\dot{m}_{w j} C_{w}\left(T_{w j}(0, t)-T_{w j}\left(L_{e}, t\right)\right)\right]
$$

where $Q_{w t j}$ is stated in equation (2), $T_{w j}\left(L_{e}, t\right)$ is in equation (5), $G_{j}$ and $Y_{j}$ are defined in (3) and (4), respectively.

Heat Balance of Tube

The heat balance of tube at transient condition is

$$
\frac{d T_{t j}}{d t}=\frac{1}{M_{t j} C_{t}}\left[Q_{w t j}-Q_{t v j}\right]
$$


where

$$
Q_{t v j}=h_{t v} A_{o j}\left(T_{t j}-T_{\ell v}\right)
$$

$Q_{w t j}$ is stated in equation (2).

Eeat Balance of Liquid on Tube and Vapor in Vessel

The enthalpy balance is

$$
\begin{aligned}
& \mathrm{H}_{\ell} \frac{\mathrm{dM}}{\mathrm{dt}}+\mathrm{H}_{\mathrm{v}} \frac{\mathrm{dM}}{\mathrm{dt}}+\left(M_{\ell} C_{\ell}+M_{\mathrm{v}} \mathrm{C}_{\mathrm{v}}\right) \frac{\mathrm{dT} \mathrm{T}_{\mathrm{v}}}{\mathrm{dt}}
\end{aligned}
$$

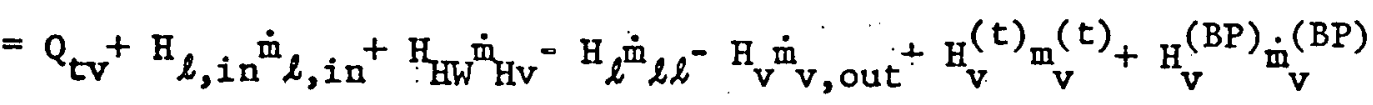

This equation may be written for $\frac{\mathrm{dT}_{\ell v}}{\mathrm{dt}}$ later.

Heat Balance of Liquid in Hotwell

$$
\mathrm{M}_{H W} C_{H W} \frac{d T_{H W}}{d t}=C_{\ell}\left(T_{\ell v}-T_{H W}\right) \dot{m}_{\ell \ell}-\lambda\left(T_{H W}\right) \dot{m}_{H v}
$$

or

$$
\frac{d T_{H W}}{d t}=\frac{1}{M_{H W} C_{H W}}\left[C_{\ell}\left(T_{\ell v}-T_{H W}\right) \dot{m}_{\ell \ell}-\lambda\left(T_{H W}\right) \dot{\mathrm{m}}_{H v}\right]
$$

\section{Mass Balances}

The vapor mass balance is

$$
\frac{d M}{d t}=\dot{m}_{l v}+\dot{m}_{v}^{(t)}+\dot{m}_{v}^{(B P)}+\dot{m}_{H v}-\dot{m}_{v, \text { out }}
$$

Mass balance of liquid ammonia on each subsystem is 
where

$$
\begin{aligned}
& \frac{\mathrm{dM}}{\mathrm{dt}}=\dot{\mathrm{m}}_{\ell, \text { in }}-\dot{\mathrm{m}}_{\ell \mathrm{V} 1}-\dot{\mathrm{m}}_{\ell \ell 1} \\
& \frac{\mathrm{dM}}{\mathrm{dt}}=\dot{\mathrm{m}}_{\ell \ell 1}-\dot{\mathrm{m}}_{\ell \mathrm{v} 2}-\dot{\mathrm{m}}_{\ell \ell 2} \\
& \left.\frac{\mathrm{dM}_{\ell 3}}{\mathrm{dt}}=\dot{\mathrm{m}}_{\ell \ell 2}-\dot{\mathrm{m}}_{\ell \mathrm{V} 3}-\dot{\mathrm{m}}_{\ell \ell}\right) \\
& \dot{\mathrm{m}}_{\ell \ell j}=\frac{2 p \ell^{g}}{3 v}\left[\frac{\mathrm{M}_{\ell j}}{\mathrm{~N}_{j}{ }^{\mathrm{l}} \ell_{\mathrm{oj}} \int_{\Delta}^{\pi-\Delta} \sin ^{-1 / 3} y d y}\right]
\end{aligned}
$$

The total of them are

$$
\begin{aligned}
& \dot{\mathrm{m}}_{\ell v}=\sum_{j} \dot{\mathrm{m}}_{\ell v j} \\
& \dot{M}_{\ell}=\sum_{j} M_{\ell j} \\
& Q_{t v}=\sum_{j} Q_{t v j}
\end{aligned}
$$

mass balance of liquid in the hotwell is

$$
\frac{d M_{H W}}{d t}=\dot{\mathrm{m}}_{\ell \mathcal{L}}-\dot{\mathrm{m}}_{\mathrm{Hv}}-\dot{\mathrm{m}}_{\mathcal{L}, \text { out }}
$$

\section{Derivation of the State Equation for Vapor Temperature}

The state equation for $T_{\mathcal{L}}$ can be derived from equation ( 8 ) with the assumption that the vapor in the condenser is in the saturated state and that it also follows the ideal gas law. That is,

$$
\mathbf{P}=P_{\text {sat }}\left(\mathrm{T}_{\ell v}\right)=\frac{\mathrm{M}_{\mathrm{v}}}{\underline{\mathrm{M}}} \frac{\mathrm{RT} \ell \mathrm{v}}{\mathrm{V}} .
$$


Therefore $\frac{d M_{v}}{d t}=\frac{M V}{R}\left[\frac{1}{T_{\ell v}}\left(\frac{\partial P_{s a t}}{\partial T}\right)_{T_{\ell v}}-\frac{P_{s a t}{ }^{(T} \ell v}{T_{\ell v}}\right]^{2} \frac{d T / v}{d t}$

Additionally, equations (12) and (14) can be combined

$$
\frac{\mathrm{d}\left(\mathrm{M}_{\ell}\right)}{\mathrm{dt}}=\dot{\mathrm{m}}_{\ell, \text { in }}-\dot{\mathrm{m}}_{\ell v}-\dot{\mathrm{m}}_{\ell \ell}
$$

Equation (9) becomes

$$
\begin{aligned}
& H_{v}\left(\dot{\mathrm{m}}_{\ell v}+\dot{m}_{v}^{(t)}+\dot{m}_{v}^{(B P)}+\dot{\mathrm{m}}_{H v}-\dot{\mathrm{m}}_{\mathrm{v}, \mathrm{Out}}\right)+\mathrm{H}_{\ell}\left(\dot{\mathrm{m}}_{\ell, i \mathrm{n}}-\dot{\mathrm{m}}_{\ell v}-\dot{\mathrm{m}}_{\ell \ell}\right)+\hat{\mathrm{C}} \frac{\mathrm{dT}}{\mathrm{dt}} \\
& =Q_{t v}+\dot{m}_{v}^{(t)} H_{v}^{(t)}+\dot{m}_{v}^{(B P)} H_{v}^{(B P)}+H_{\ell, i n} \dot{m}_{\ell, i n}+H_{H W} \dot{m}_{H v}-H_{\ell} \dot{m}_{\ell l}-H_{v} \dot{m}, \text { out }
\end{aligned}
$$

where

$$
\hat{C} \equiv M_{v} C+M_{\ell} C_{\ell}
$$

$$
\text { or } \begin{aligned}
\left(\mathrm{H}_{\mathrm{v}}-\mathrm{H}_{\ell}\right) \dot{\mathrm{m}}_{\ell v}+\hat{\mathrm{C}} \frac{\mathrm{dT} l \mathrm{v}}{\mathrm{dt}}=\mathrm{Q}_{\mathrm{tv}}+\left(\mathrm{H}_{\mathrm{v}}^{(\mathrm{t})}-\mathrm{H}_{\mathrm{v}}\right) \dot{\mathrm{m}}_{\mathrm{v}}^{(\mathrm{t})}+\left(\mathrm{H}_{\ell, \text { in }}-\mathrm{H}_{\ell}\right) \dot{\mathrm{m}}_{\ell, \text { in }} \\
+\left(\mathrm{H}_{\mathrm{HW}}-\mathrm{H}_{\mathrm{v}}\right) \dot{\mathrm{m}}_{\mathrm{Hv}}+\left(\mathrm{H}_{\mathrm{v}}^{(\mathrm{BP})}-\mathrm{H}_{\mathrm{v}}\right) \dot{\mathrm{m}}_{\mathrm{v}}^{(\mathrm{BP})}
\end{aligned}
$$

Using equations (11) and (15) $\dot{\mathrm{m}}_{\ell v}$ can be expressed as

$$
\begin{aligned}
& -\dot{\mathrm{m}}_{\ell v}=\dot{\mathrm{m}}_{\mathrm{v}}^{(t)}+\dot{\mathrm{m}}_{\mathrm{v}}^{(B P)}-\frac{d \mathrm{~d}}{\mathrm{dt}}+\dot{\mathrm{m}}_{\mathrm{HV}}-\dot{\mathrm{m}}_{\mathrm{v}, \text { out }} \\
& =\dot{\mathrm{m}}_{v}^{(t)}+\dot{\mathrm{m}}_{v}^{(B P)}-\hat{B} \frac{d T}{d t}+\dot{\mathrm{m}}_{\mathrm{HV}}-\dot{\mathrm{m}}_{\mathrm{v}, \text { out }} \\
& B=\frac{M V}{R}\left[\frac{1}{T_{\ell v}}\left(\frac{\partial P_{s a t}}{\partial T}\right)_{T_{\ell V}}-\frac{P_{s a t}\left(T_{\ell V}\right)}{T_{\ell v}^{2}}\right]
\end{aligned}
$$

where

In addition, the latent heat of vaporization $\lambda$ can be used. That is,

$$
\lambda=\mathrm{H}_{\mathrm{v}}-\mathrm{H}_{\ell}
$$


and

$$
\begin{aligned}
& \mathrm{H}_{\mathrm{v}}^{(t)}-\mathrm{H}_{\mathrm{v}}=\mathrm{C}_{\mathrm{v}}\left(\mathrm{T}_{\mathrm{v}}^{(\mathrm{t})}-\mathrm{T}_{\ell \mathrm{v}}\right) \ldots \\
& \mathrm{H}_{\mathrm{v}}^{(\mathrm{BP})}-\mathrm{H}_{\mathrm{v}}=\mathrm{C}_{\mathrm{v}}\left(\mathrm{T}_{\mathrm{v}}^{(\mathrm{BP})}-\mathrm{T}_{\ell \mathrm{v}}\right) \\
& \left(\mathrm{H}_{\ell, \text { in }}-\mathrm{H}_{\ell}\right)=\mathrm{C}_{\ell, \text { in }}\left(\mathrm{T}_{\ell, \text { in }}-\mathrm{T}_{\ell v}\right) \\
& \left(H_{H W}-H_{v}\right)=C_{v H W}\left(T_{H W}-T_{d v}\right)
\end{aligned}
$$

Finally, the state equation of vapor temperature is

$$
\begin{aligned}
\frac{d T}{d t} & =\frac{1}{(\lambda \hat{B}+\hat{C})}\left[Q_{t v}+C_{v}\left(T_{v}^{(t)}-T_{\ell v}\right) \dot{m}_{v}^{(t)}+C_{v}\left(T_{v}^{(B P)}-T_{\ell v}\right) \dot{m}_{v}^{(B P)}+\dot{\lambda}\left(\dot{m}_{v}^{(t)}+\dot{m}_{v}^{(B P)}\right.\right. \\
& \left.+\dot{m}_{H v}-\dot{m}_{v, O u t}\right)+C_{\ell, i n}\left(T_{\ell, i n}-T_{\ell v}\right) \dot{m}_{\ell, i n}+C_{v H W}\left(T_{H W}-T_{\ell v}\right) \dot{m}_{H v}
\end{aligned}
$$

where $\lambda$ is stated in equation (18), $\hat{B}$ is in equation (17), $\hat{C}$ is in equation (16) and $Q_{t v}$ in in equation (8).

\section{B. Particular Considerations}

For condensers $\dot{\mathrm{m}}_{\ell, \text { in }} \dot{\mathrm{m}}_{\mathrm{v}, \text { out }}$ will be zexo. On the other hand, for evaporators, $\dot{\mathrm{m}}_{\mathrm{v}}^{(\mathrm{t})}$ and $\dot{\mathrm{m}}_{\mathrm{v}}^{(\mathrm{BP})}$ will be zero. At normal operations $\dot{\mathrm{m}}_{\ell v}$ will be positive for evaporator and negative for condenser. 


\subsubsection{Further Refinement of the Model}

The present model using lumped subsystems will be compared with

the calculated solution from the exact transient analysis which is described In the appendix. Through comparison, the optimum number of horizontal tubes or length of vertical tube will be decided such that minimum computationai effort will be required for reasonable accuracy. The delay times $t_{0}$ will also be considered as a calibration parameter to allow for some flexibility of this model.

The model will also be extended to the case of vertical fluted tubes with proper modifications of the forms of the equations.

The modeling of the shear stress dominated film flow will also be studied, however it will not be included in the present modeling effort. 


\subsubsection{References for Section 3.7}

1. Butterworth, D., "Developments in the Design of Shell and Tube Condensers," ASME Paper No. 77-WA/HT-24.

2. Fletcher, L.S., Sevnas, V., and Parker, W., "Evaporation Heat Transfer Coefficients for Thin Sea Water Films on Horizontal Tubes," Ind. Eng. Chem., Process Des. Dev., Vo1. 14, No. 4 (1975) PP 411-416.

3. Gamic, E.N. and Czikk, A.M., "An Analytical Model of the Sprayed Bundle Evaporators," Union Carbide Linde Division. OTEC Contract $E(49-18)-2448$.

4. Westerberg, A., Suuberg, E. and Yao, S., et al, "A Dynamic Simulation Program for OTEC," CMU-Rept. OTEC Contract No. EG-7-03-C1569.

5. Ishihara, R., Paten, J., and Taborek, J., "Critical Review of Correlations for Predicting Two-phase Flow Pressure Drop Across Tube Banks," ASME Paper No. 77-WA/HT-23.

6. Yung, D., Lorenz, J., and Gamic, E., "Vapor-Liquid Interaction and Entraiment in She11-and-Tube Evaporators," ANL-OTEC-78-2.

7. Ihiratowicz, E., Gumkowski, S., and Mikidlewicz, L., "Experimental Study of Evaporation and Breakdown of Thin Liquid Films Driven by Shear Stresses," ASME Paper No. 77-WA/HT-7.

8. Chun, K. and Seban, R., "Performance Prediction of Falling Film Evaporators," Trans. ASME. J. of Heat Transfer, Nov. 1972, pp 432-436.

9. Lorenz, J. and Yung, D., "An Analysis of Heat Transfer in Horizontal Tube Falling Film Evaporators," ANL-OTEC-78-1.

10. Isenberg, J. and Gutfinger, C., "Heat Transfer to Draining Film," Int. J. Heat Mass Transf., Vol. 16, pp 505-512 (1973).

11. Solan, A. and Zfat1, A., "Heat Transfer in Laminar Flow of a Liquid Film on a Horizontal Cylinder," 5th Int. Heat Transfer Conference, Paper FC 2.9, 1974.

12. Collier, J., "Convective Boiling and Condensation," McGraw Hill Co., 1972.

13. Nusse1t, W., "Die Oberflachenkondensation des Wasserdampfes," Zeitschr. Ver. deutsh. Ing., 60, 541 and 569 (1916).

14. Seban, R., "Transport to Falling Film," Paper K-30, 6th Int. Beat Transfer Conference (1978). 


\subsection{PI Controller}

A PI controller unit models a conventional proportional, integral control device. Figure 13 illustrates a PI controller unit. The mode1 is as follows.

$$
\begin{aligned}
& \mathrm{CONT}-\mathrm{KP} *(E R R+(1 / \mathrm{KI}) * \operatorname{INTERR})=\varnothing \\
& \frac{\mathrm{d} I N T E R R}{\mathrm{dt}}=\mathrm{ERR}, \operatorname{INTERR}(t=\phi)=\varnothing \\
& \mathrm{ERR}-(\mathrm{SP}-\mathrm{MEAS})=\varnothing
\end{aligned}
$$

where

$$
\begin{aligned}
& \text { CONT Controller output signal } \\
& \text { KP. } \quad \text { Proportional constant } \\
& \text { KI } \quad \text { Integral constant } \\
& \text { ERR Error signal } \\
& \text { INTERR Integral of the error signal } \\
& \text { t } \quad \text { Time, } s \\
& \text { MEAS } \text { Measured variable value } \\
& \text { SP } \quad \text { Set point for measured variable }
\end{aligned}
$$




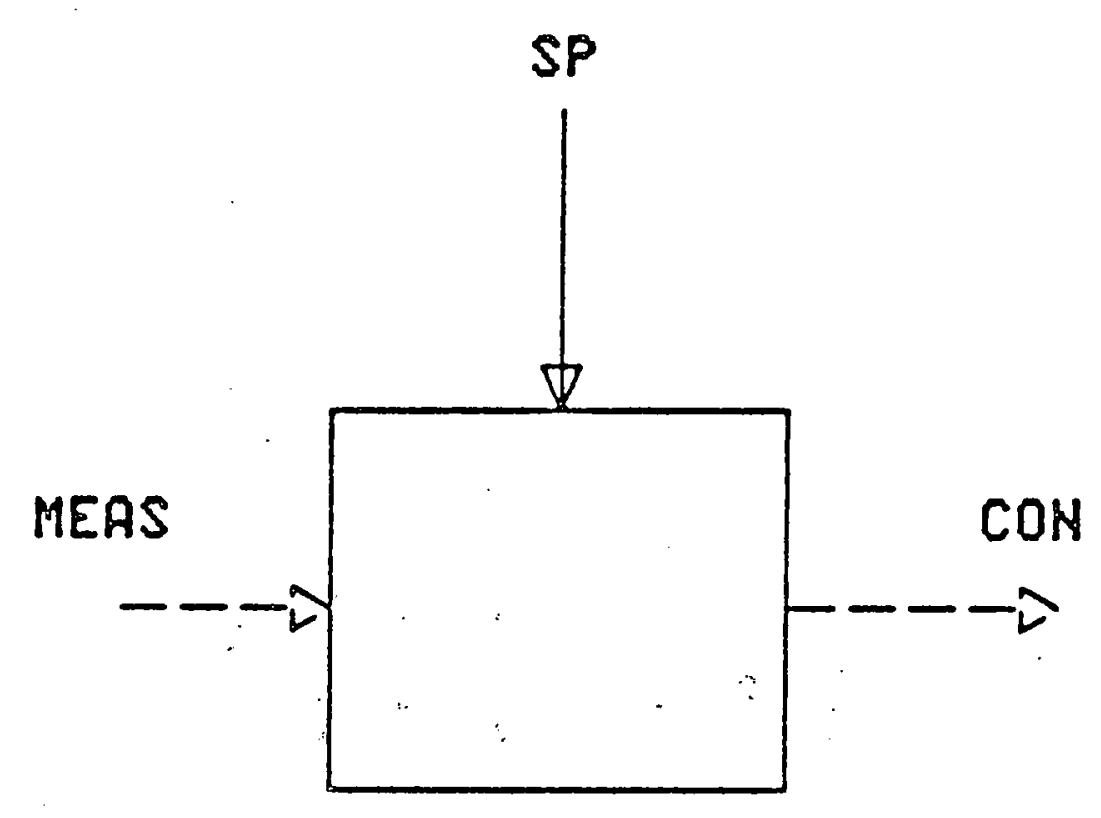

Figure 13 A PI Controller 


\section{Software System Design for OSCAR-1}

\subsection{Introduction}

In this section we shall cover the system design aspects for developing the OSCAR-1 system. First, in Section 4.2 we shall present an abstract view of the dynamic and steady-state models for an OTEC plant. This view will make it clear that simulation is, in the abstract sense, an exercise in solving nonlinear ODE's and algebraic equations. It also includes discovering points in time when tho modeling equations will change because, for example, a liquid film is finally hot enough to start boiling. The next sections will concentrate on solving the initial starting condition for a plant, which is the solving of a steady-state for the plant. The initial plant steady-state requires solving simultaneous nonlinear algebraic equations: We shall solve using the Newton-Raphson method which is presented in section 4.3, using sparse matrix methods to solve the resulting linear equations at each iteration. We discuss in general terms the numerical precautions needed to effect a solution using this technique.

The overall view of OSCAR broken into subsystems is presented in Section 4.4. We then describe the function of each subsystem.

The last sections (Sections $4.5,6,7$ ) continue to concentrate on the steady-state problem, giving a very abstract view of the software design strategy together with examples to illustrate its usefulness. We hope to convince the reader that the approach is simple (and thus in our view "elegant") and indeed will form the basis of an extremely versatile steady-state subystem. 


\subsection{Abstract Dynamic and Steady-State Mode1}

The simulation of the dynamic behavior of an OTEC plant can be viewed in general terms as the solving of the following equations. We call it the dynamic simulation problem (DS).

$$
\begin{aligned}
\text { State Equations: } & \dot{x}=f(x, z, u) \\
\text { Algebraic Equations: } & g(x, z, u)=0 \\
\text { Point Constraints: } & p\left(x\left(t_{i}\right), z\left(t_{i}\right), u\left(t_{i}\right)=0\right.
\end{aligned}
$$

where

$$
\begin{aligned}
& \mathrm{X}^{\in} \mathrm{E}^{\mathbf{n}} \text { are state variables } \\
& z \in E^{\mathrm{m}} \text { are algebraic variables } \\
& \mathrm{uEE}^{\mathbf{r}} \text { are variables whose values must be supplied } \\
& \text { from elsewhere; the independent variables in } \\
& \text { the problem } \\
& f: E^{n+m+r} \rightarrow E^{n} \\
& \text { g: } E^{\mathrm{n}+\mathrm{m}+\mathrm{r}} \rightarrow \mathrm{E}^{\mathrm{m}} \\
& p_{1}: E^{n+m+r} \rightarrow E^{q_{i}}\left(q_{i} \text { normally equals } 1\right)
\end{aligned}
$$

The point constraints are used to define times $t_{i}$ when discrete events occur. An example is a constraint which detects transition from a no boiling to a boiling condition for the liquid film on a tube in the evaporator unit. Another is the closing completely of a control valve. The flow will drop to zero and many calculations become unnecessary. In both cases the modeling equations for the process are altered by the event. 
This problem is therefore one with $n$ state equations, one for each of the state variables $x_{i}$, m algebraic equations, one for each of the algebraic variables $z_{j}$ and $r$ independent variables $u_{k}$.

To solve we also need an initial condition which is a steady-state condition if it satisfies the equations (call it the steady-state problem $(\mathrm{SS}))$

$$
\begin{gathered}
\dot{x}=f\left(x\left(t_{0}\right), z\left(t_{0}\right), u\left(t_{0}\right)\right)=0 \\
g\left(x\left(t_{0}\right), z\left(t_{0}\right), u\left(t_{0}\right)\right)=0
\end{gathered}
$$

We can consider the solving of the original steady-state condition as a problem distinct from the problem of moving from that steady-state through time. Thus, as we stated earlier, we really have two problems for OSCAR: (1) the original steady-state problem (SS) and (2) the dynamic simulation problem (DS).

Again we can generalize our view of problem (SS) by establishing a repartitioning of all of the variables $(x, z, u)$ into two sets $(s, d)$ such that

$$
\begin{aligned}
& f(s, d)=0 \\
& g(s, d)=0 \\
& s \in E^{r} \quad d \in E^{n+m}
\end{aligned}
$$

and such that each of the variables in the sets $(x, z, u)$ is classified into either of the sets $s$ and $d$ according to its use when solving problem (SS). The r varlables in set $s$ are the "independent" (or "specified) variables whose values the user wishes to specify, and the $n+m$ vartables in set $d$ are the "dependent" variables whose values we must calculate using the $n+m$ equations $f=0$ and $g=0$. When the variables $s$ are specified and the variables $d(s)$ are calculated from $f=\phi, g=\phi$, then all variables $x, z$ and $u$ have initial values consistent with the steady-state equations. 


\subsection{The Newton Raphson Me thod}

The most abstract view of solving problem (SS') is that one is solving a set of algebraic, probably nonlinear and simultaneous, equations. To solve nonlinear algebraic equations arising from the model of a physical process, we intend to use the Newton-Raphson method together with sparse matrix methods to solve the large sets of sparse linear equations which result at each iteration.

Briefly the Newton-Raphson method is a method to solve the non linear equations iteratively by approximating the functions at the current guess for the solution by a linearized version of them. Then the linearized version is solved to find how to change the variable values such that the linearized functions are satisfied. The iteration is repeated until the nonlinear functions become essentially zero in value. The Newton-Raphson equations are easily derived as follows.

The problem is to solve for $\underline{v}=\underline{v}^{*}$. such that

$$
\underline{F}\left(\underline{v}^{*}\right)=\underline{0}
$$

We expand $\underline{F}(\underline{v})$ about the current guess for $\underline{v}$ in a Taylor series up to firstorder only.

$$
\underline{F}(\underline{v}+\Delta \underline{v}) \approx \underline{F}(\underline{v})+\left(\frac{\partial F}{\partial \underline{v}}\right)_{\underline{v}} \underline{\underline{v}}
$$

Setting $\underline{F}(\underline{v}+\underline{\Delta})=\underline{0}$ gives the Newton-Raphson equations

$$
\left(\frac{\partial \underline{F}}{\partial \underline{v}}\right)_{\underline{v}} \Delta \underline{v}=-F(\underline{v})
$$


which are linear in the unknowns $\underline{\Delta v}$. The matrix $\frac{\partial F}{\partial \underline{v}}$ is the Jacobian matrix

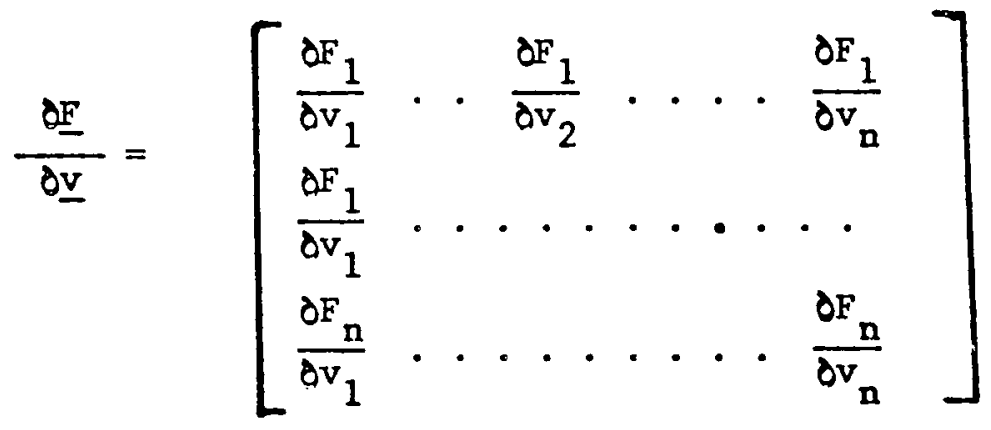

It is these linear equations we must solve at each iteration. Then $\underline{v}$ becomes replaced by $\underline{\mathrm{v}}+\underline{\Delta} \underline{\mathrm{v}}$, and we repeat until $\underline{\mathrm{F}}(\underline{\mathrm{v}}) \approx \underline{0}$.

The Jacobian matrix is large and sparse. Most partial derivatives contained in it are zero because most functions $F_{j}$ explicitly contain only a few (say 1 to 10) of the unknowns. Thus "sparse matrix" methods can be effectively used; we have frequently used the sparse matrix routines developed. at AERE Harwe 11 in England and intend to use them here. The particular routines will be the MA28 routines.

To solve such a problem effectively one must take care in handling each of the following considerations.

1) Variable initialization - an effective and convenient scheme must be available for the user to provide initial guessed values and/or for the system to generate intial guessed values for all of the problem varlables.

2) Variable scaling - physically meaningful scale factors must be generated for each problem variable so the test (for example)

$$
\sum_{j}\left(\Delta \hat{v}_{f}\right)^{2} \leq \varepsilon_{1}
$$


Is meaningful and so a numerically stable pivot sequence is selected when solving the linear equations. The $\hat{v}_{j}$ are rescaled problem variables with nominal values of unity if scaling is correctly done.

3) Equation scaling - physically meaningful scale factors must be developed for each equation so the test (for example)

$$
\sum_{1} \hat{F}_{1}^{2}(\underline{v}) \leq \varepsilon_{2}
$$

is meaningful, and, again, so a numerically stable pivot sequence is selected when solving the linear equations. The $\hat{F}_{i}$ are rescaled functions $F_{i}$ such that each term in them is of nominal value unity.

4) Removal of "poles" - the modeling equations have to be carefully written so no divisions occur which could give rise to a pole in either the evaluation of the function itself or in a partial derivative of the function. An example is to rewrite

$$
F_{1}=\exp (10 / T)-6 \mathrm{~T}=0
$$

as

$$
\begin{aligned}
& F_{i}^{*}=\exp (y)-6 T=0 \\
& F_{1}^{* *}=y T-10=0,
\end{aligned}
$$

the latter formulation having no pole at $T=0$. Another example is to rewrite

as

$$
\begin{gathered}
F_{k}=\ln (w)+x=0 \\
F_{k}^{*}=z+x=0 \\
F_{k}^{* *}=e^{z}-w=0
\end{gathered}
$$

the latter set avolds the pole at $w=0$ which is found when taking partial derivatives $\left(\frac{\partial F_{k}}{\partial w}=1 / w\right)$. 


\subsection{System View of OSCAR-1}

Figure 14 gives a system's view of the OSCAR-1 software system design. It shows first a partitioning of the simulation problem into a steady-state problem (SS') and a dynamic simulation problem (DS). The design of OSCAR is based on the view that we shall first create a file of variable values representing an (SS) calculation. A number of subsystems interacts with this file and are as follows.

1) User Input - For inputting the structure of the OTEC plant, describirg the initialization sequence, supplylng initial variable values.

2) Initialize Variables - For computing initlal variable value guesses In terms of the small set of initial guesses supplied by the user.

3) Scale Variables and Equations - For scaling variables and equations as discussed earlier.

4) Selection of Variables in set $\mathbf{S}$ - The user now selects the variables which he wants held at their current values, leaving the rest to be solved for by the system in terms of these using the equations defining the steady-state. This is done by user input.

5) Convergence of SS Equations - The equations defining the steady-state are converged using a Newton-Raphson scheme. For each equation, the partial derivatives necessary to establish the Jacobian matrix are required as well as the evaluation of the functions themselves, which should be zero at a converged solution.

6) Report Generation - At any time the contents of the SS file can be printed in a readable format. Thus the user can see preliminary, intermediate and converged values for his OTEC plant. 


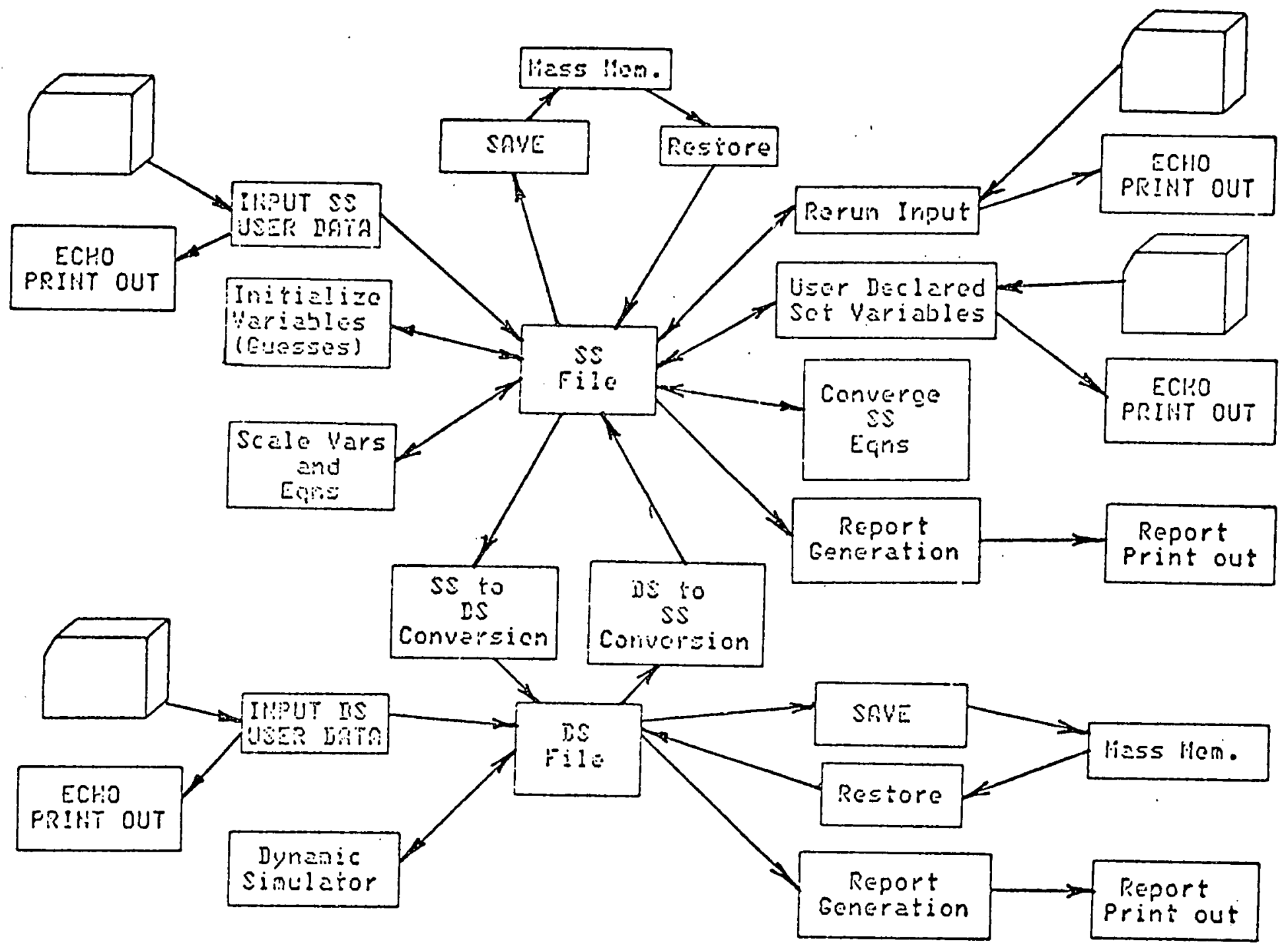


7) Rerun - If the plant structure is changed in a correct manner the user can input different values for some of the variables and reinitialize using previous values where possible. Then he can select a different set of variables to calculate and reconverge the SS equations.

8) Save, Restore - The SS file can be saved and restored at any point, permitting the results of earlier studies to be used to aid in calculating new ones:

9) SS to DS Conversion - A DS (Dynamic Simulation) data file is created from the data in an SS file. The DS file will need storage of variables versus time and is anticipated at present to be of a different structure from an SS file.

10) Input DS User Data - To perform a dynamic simulation, several additional input data are needed, such as length of simulation, initial values for holdup variables (whose values are not set by steady-state calculations), independent variable behavior versus time, etc.

11) Dynamic Simulator - The details here are not worked out yet, but this package will perform the actual simulation versus time. We shall use the EPISODE package (modified) here.

12) SAVE, RESTORE - The DS file can be saved onto and restored from a mass memory device. Thus results from one run can be used to initiate another. Also a run can be interrupted and continued later.

13) Report Generation - A report of the current contents of the DS file in readable format will be written to an output file or device.

14) DS to SS Conversion - The contents of a DS file at a user specified instant in time will be converted to an SS file so reruns using the SS software may be performed. 


\subsection{Generators and Packets}

In this section we present and discuss the current approach to the internal design of the SS subsystem. This design represents a generalization of previous software system designs to perform such calculations. It is, we believe, both simple and powerful in concept. The simplicity will make both implementing it and teaching about its use much less difficult than one might otherwise expect. It is certainly more straightforward and powerful than any previous systems we have developed.

The simplicity arises from the use of three basic concepts: generators, equation packets and variable packets. A generator is a subroutine which "generates" partial derivatives for the Jacobian matrix. It generates these partial derivatives for a limited portion of the Jacobian matrix and corresponds with one type of calculation such as that for a unit mode1. The rows and columns in the Jacobian matrix, into which these partial derivatives are stored, are identified as the corresponding equation packets and variable packets for the generator. Figure 15 illustrates.

Several options are possible. We include the following in the current design.

Several generators may use the same variable and/or equation packets. The example in Figure 16 illustrates. A small plant is illustrated - a pipe followed by a pump. For each connecting stream, we identify a variable packet which contains the values for the stream's flowrate, temperature and pressure. For each unit we include a variable packet which contains values for the variables needed to simulate the unit aside from its input and output stream variable values. A variable packet is 111 us trated by a horizontal line, an equation packet by a vertical line and a generator by a box. Connecting packets to the generator with a dashed line 


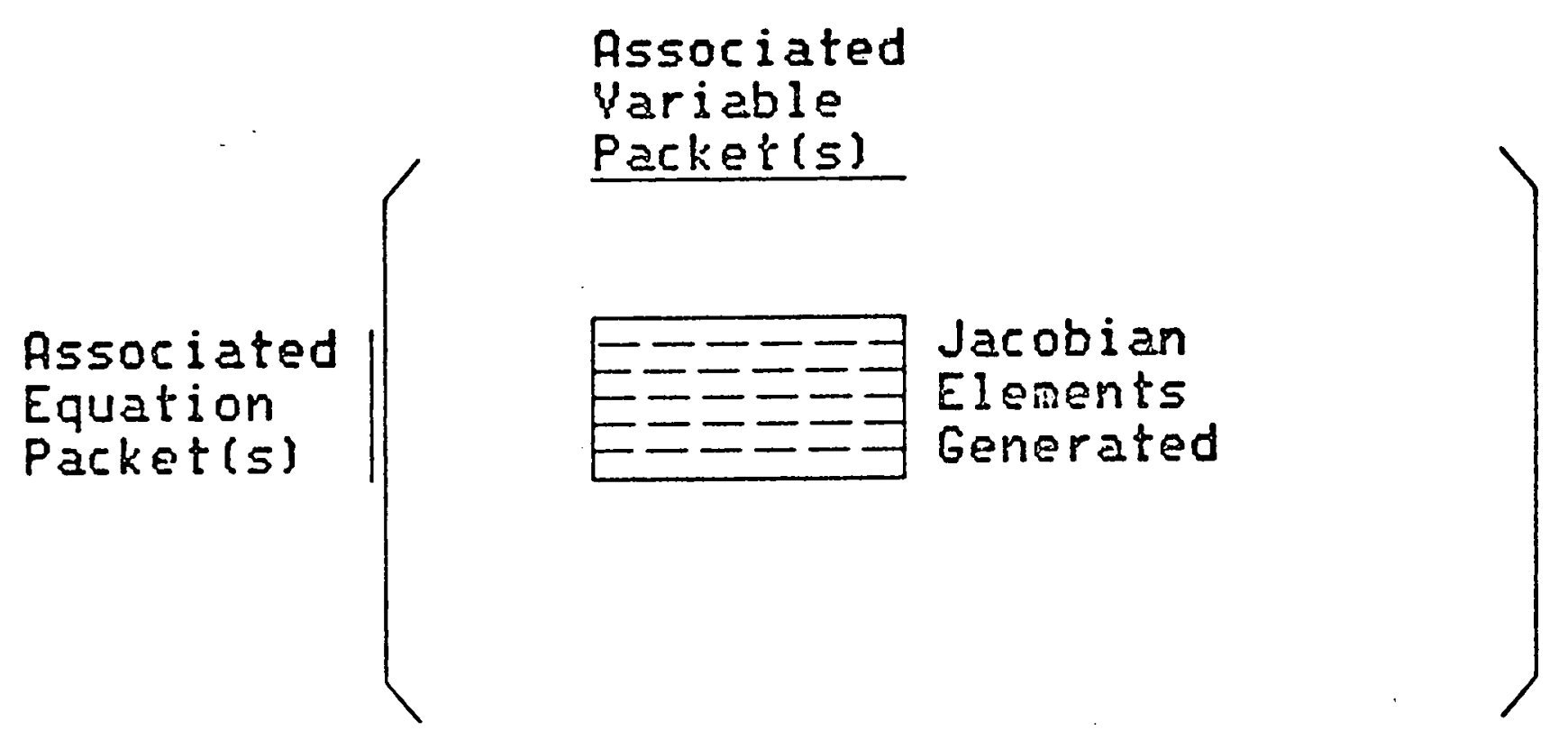

Figure 15 The Jacobian Elements Generated By a Generator in the Particular Rows and Columns Identified as the Associated Equation and Variables Packet(s) 

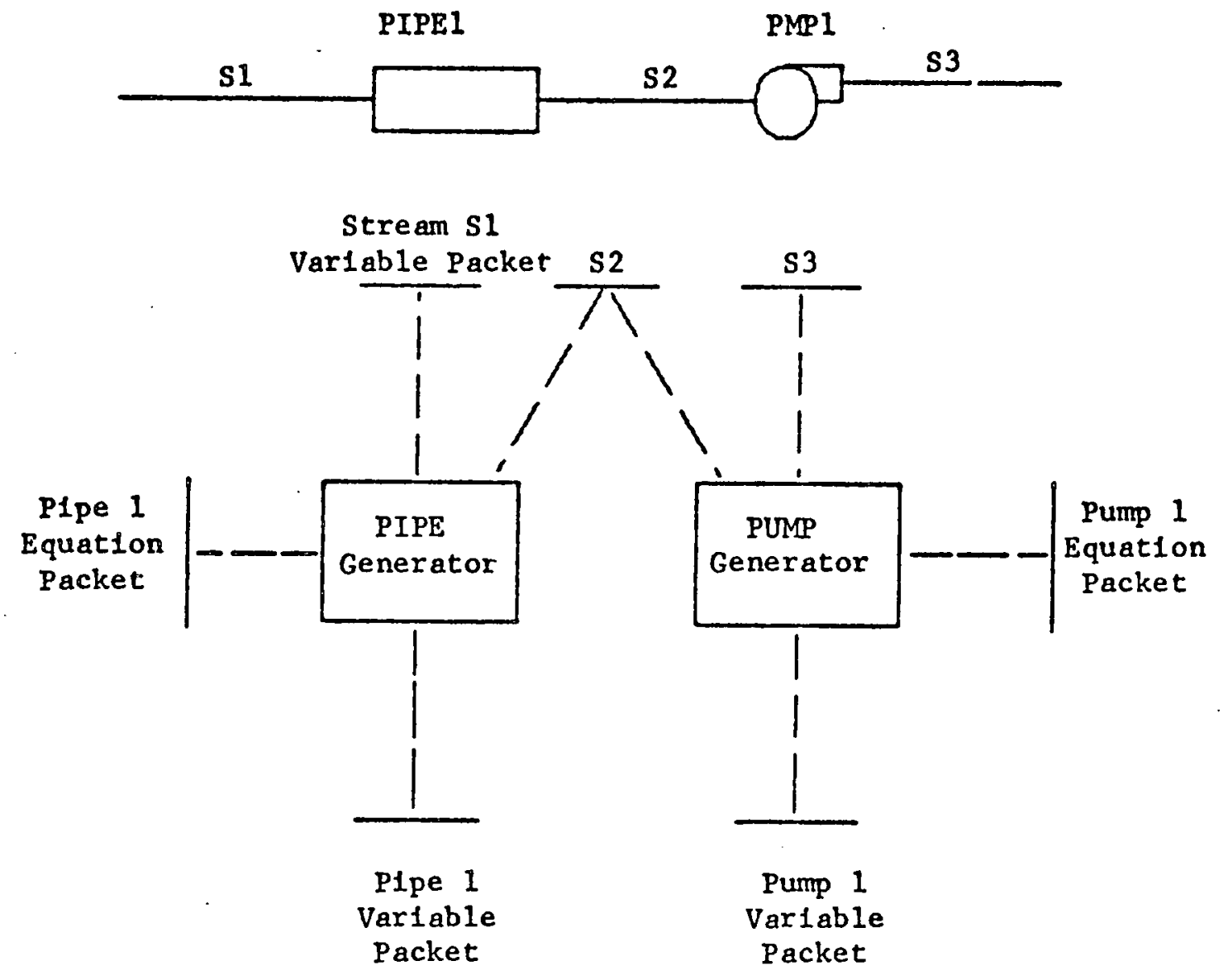

(b

Figure 16. Generator, Equation and Varlable (GEV) Dlagram for a Simple Plant. (a) is the simple plant, a plpe followed by a pump. (b) 13 the GEV dlagram. Varlable packets are horlzontal 11nes, equation packets are vertical lines, generators are boxes. 
means the generator creates non-zero Jacobian elements in the corresponding rows and columns. Both generators use the variables (columns) of stream s2, and, by doing so, the plant connectivity is automatically included, 1.e., the output stream of the pipe is the input stream of the pump.

A second example illustrates the case where two generators may access the same equation packets. Suppose the capital cost of the process in Figure 16 is desired and is the sum of capital costs for the pipe and the pump, i.e.

$$
\varphi=\varphi_{\mathrm{PIPE} 1}+\varphi_{\mathrm{PMP} 1}
$$

The GEV diagram in Figure 17 illustrates a structure to effect this calculation:

The row for the cost function (which is the sum of two functions)

will recelve contributions from both the Pipe cost generator and the Pump Cost generator. Each of these generators uses variable values from the variable packet for its respective unit and from the cost data for each.

A third example 1llustrates how physical property calculations may be isolated from unit calculations. Figure 18 illustrates for our simple plant in Figure 16a. The partially completed Jacobian matrix is also 11lustrated.

The variable packet and equation packet naming scheme allows packets to contain "subpackets." This is accomplished by allowing the user to point inside a packet by use of an index. For example, both VPPMP and $\operatorname{VPPMP}(1)$ point to the first variable in the variable packet VPPMP. To point to the third element, one uses the name $\operatorname{VPPMP}(3)$. The density variable value needed by a pump may be stored as the third item. The density generator can then be written to use as one of its variable packets a one variable long vartable packet containing only the density. By naming VPPMP(3) as that packet, one has a subpacket contained within VPPMP. 


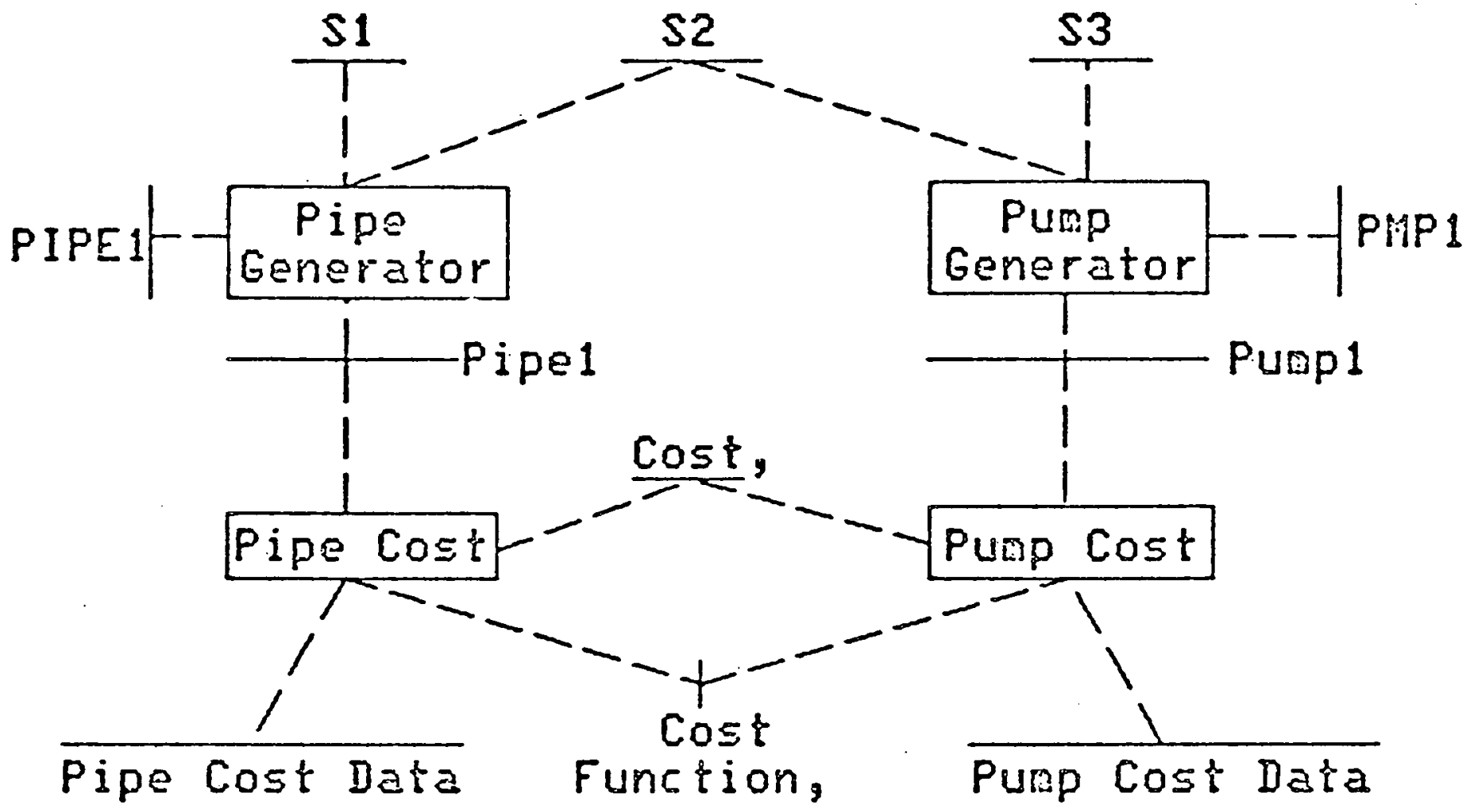

(a)

\begin{tabular}{|c|c|c|c|c|c|c|c|}
\hline & $\$ 1$ & Pipel & $\$ 2$ & PHP1 S3 & $\phi$ & $\begin{array}{l}\text { Pipe } \\
\text { Cost } \\
\text { Data }\end{array}$ & $\begin{array}{l}\text { Pupp } \\
\text { Cost } \\
\text { Data }\end{array}$ \\
\hline PIFEI & pipe & Genera & & & & & \\
\hline PMP 1 & & & usp & Generetor & & & \\
\hline $\begin{array}{l}\text { Cost } \\
\text { Funetion }\end{array}$ & & $\begin{array}{l}\text { Pipe } \\
\text { Cosi }\end{array}$ & & $\begin{array}{l}\text { Punp } \\
\text { Cost }\end{array}$ & Bost & {$\left[\begin{array}{l}\text { Pipe } \\
\text { Cosit }\end{array}\right]$} & $\left|\begin{array}{l}\text { Puing } \\
\cos i\end{array}\right|$ \\
\hline
\end{tabular}

(b)

Figure 17 The GEY Diagran (a) and Jacobian Hatrix (b) for the Sirple Plant in Figure $16 a$ When Costing is Ione 

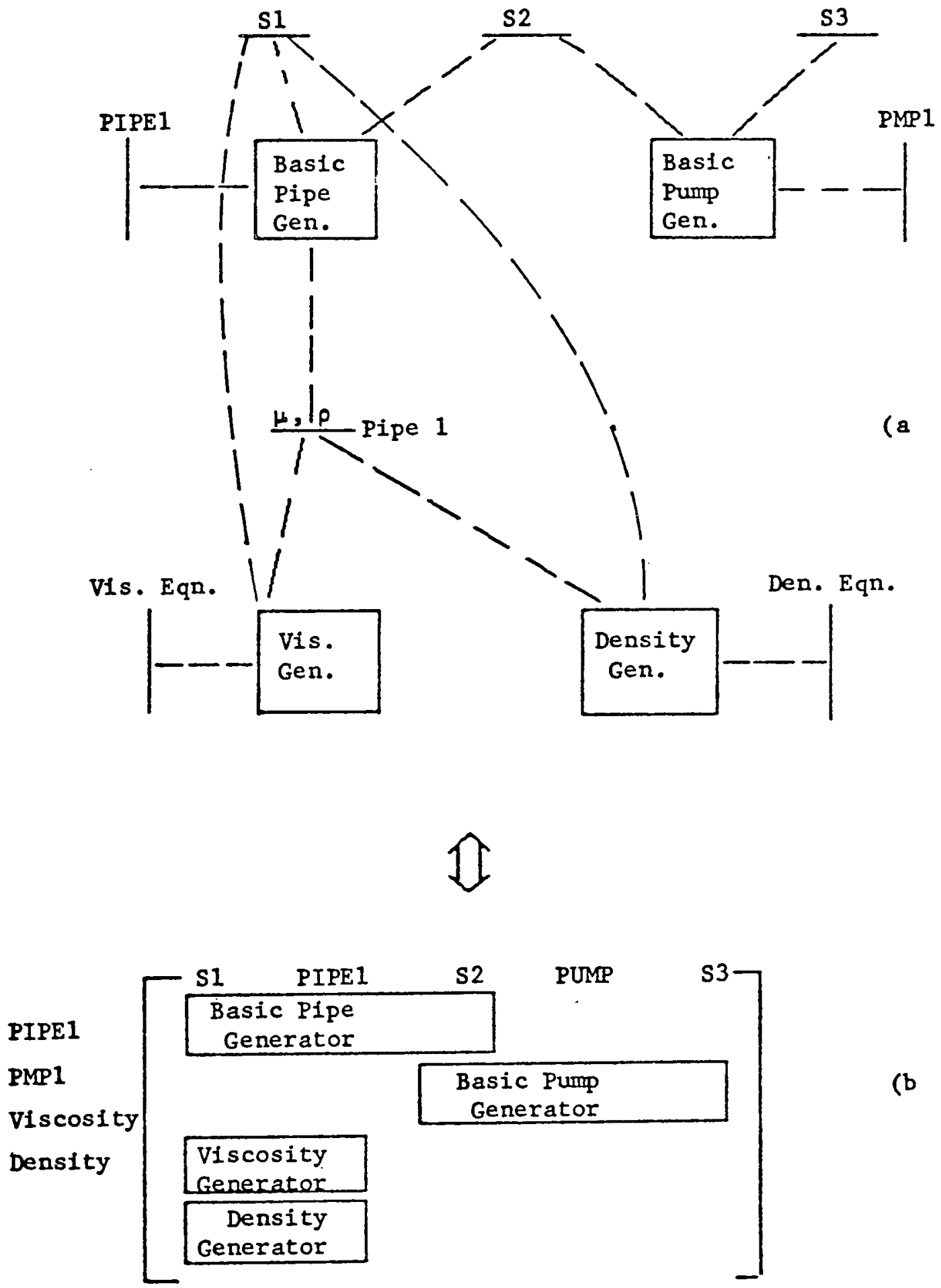

FIGURE 18. GEV Diagram (a) and Jacobian Matrix (b) for Simple Plant in Figure 16a. Illustrates inclusion of physical properties as separate generators. 


\subsection{Arbitrary User Specifications}

The user will be able to specify almost arbitrarily which variables are to be fixed in value and thus which sets are to be calculated In terms of these. Clearly, he must specify exactly the right number to give a set of $n$ equations in exactly $n$ unknowns, and also he must specify a set which leaves a nonsingular set of equations in the remaining unknowns. If he can meet these restrictions, then what he chooses to fix is otherwise arbitrary. By now the approach is probably evident. A complete nonsquare Jacobian matrix for $n$ equations in $m(>n)$ variables is created at each iteration by the generators. The column associated with fixed variables are deleted, leaving a square matrix which is then used as the coefficlent matrix for the Newton-Raphson iteration. To establish which set of variables are to be kept fixed, the user is simply establishing the index set which identifies the columns to be deleted.

\subsection{Simplifying User Input}

The user instructions for developing a plant simulation will have the format

Unit Name Generator Equation Packet List ; Variable Packet List

It may by now be seen that the user will be naming many packets and generators to affect a simulation, and, without the following ideas, he would be.

Defaults: To ease the burden of user input, the user may include DEFAULT statements which will have the form

\section{DEFAULT Generator Equation Packet List; Variable Packet List}

Any names provided here will be used as defaults in subsequent occurrences of the generator named. 
Macro-like Expansions: To ease user input when a collection of generators is always used to model a particular element, the user will be able to name as a generator one which the system will in fact identify as several and will automatically use in place of the one named. Thus a turbulent liquid pipe model could have the generator named TLPIP. The system, upon seeing this name, will substitute the generators

1. Basic Pipe Generator

2. Liquid Viscosity Generator

3. Liquid Density Generator

4. Turbulent Frfction Factor Generator

together with appropriate variable and equation packets created from those supplied by the user for the TLPIP generator.

\subsection{Dynamic System Design}

The details for the preliminary DS system design are not yet worked out. We expect we shall use many of the SS system design ideas directly. 
Appendix

Transient Studies of the Thin Film Behavior

Equation (6) in Section 2.8 is a first-order quasi-linear partial differential equation. Severe numerical instability occurs when using conventional finte difference calculations for this problem. Methods using artificial (viscosity) are also found not to be effective for this problem. However, we can obtain solutions by the method of characteristics if the lines of characteristics do not cross one another. This implies the sol"tions for transients in which one reduces the inlet flow are achievable by this method.

Following the method of characteristics, equation (6) can be written

as

$$
\begin{gathered}
\frac{d \delta}{d t}=-\frac{q w}{\rho_{l}^{h} f g}, \quad \text { and } \\
\frac{d(x / R)}{d t}=\left[\frac{3 g}{v} \sin \left(\frac{x}{R}\right)\right] \delta^{2}
\end{gathered}
$$

These latter equations give the characteristic lines. For higher mass flow rate, the slope of the characteristic lines are smaller, meaning that a thick film moves faster. Figure Al shows typical examples. To avoid the crossing of characteristic lines, the case for reducing inlet flow only are studied in detail. Typical results for the local film thickness are presented in Figures $A 2$ and $A 3$ for various transients. The films are thick at both the top and bottom of the tubes. The step change transient at the Inlet gradually smooths as it advances along the tube. 


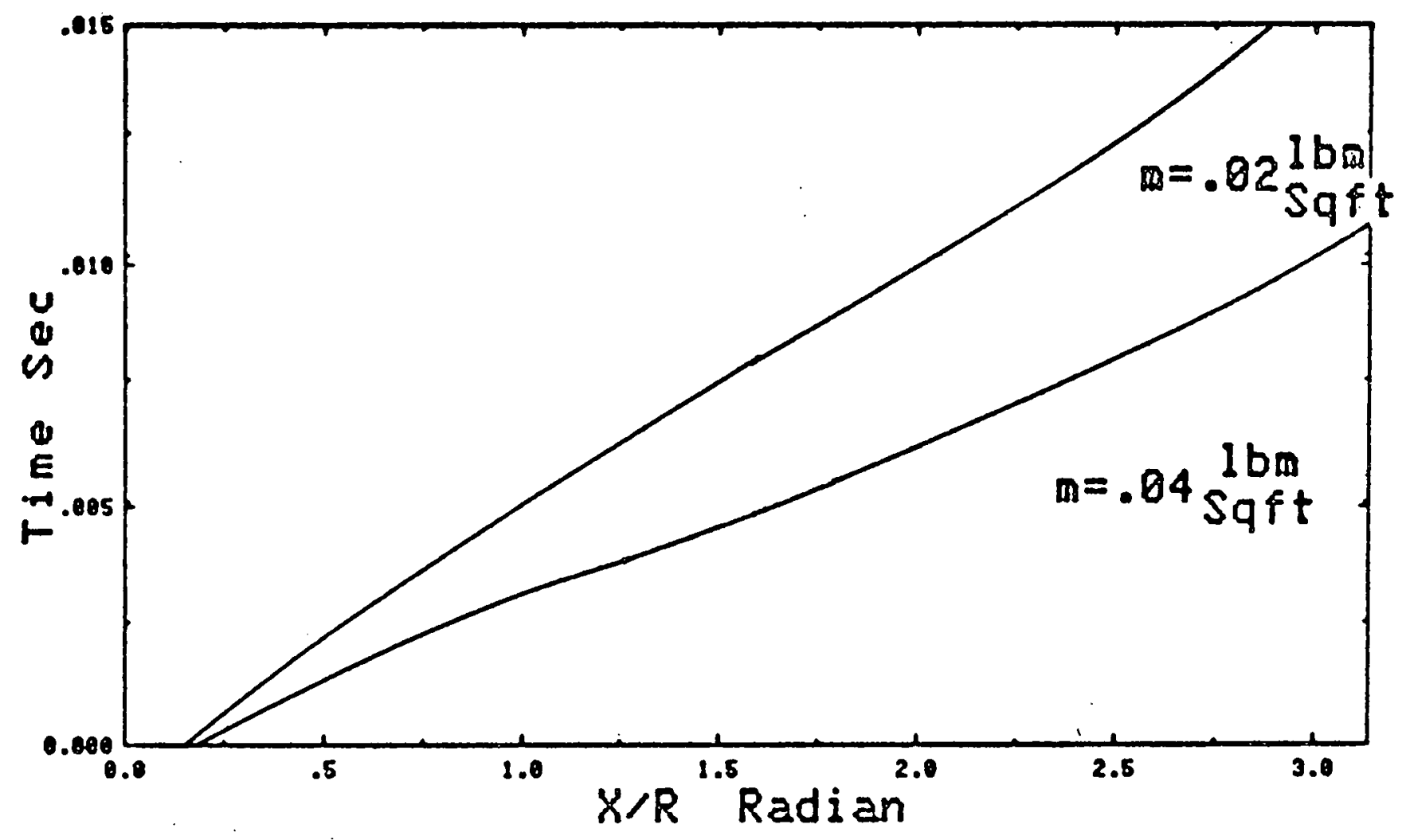

Figure A1 Flow Rate Yerse Fild Thickness 


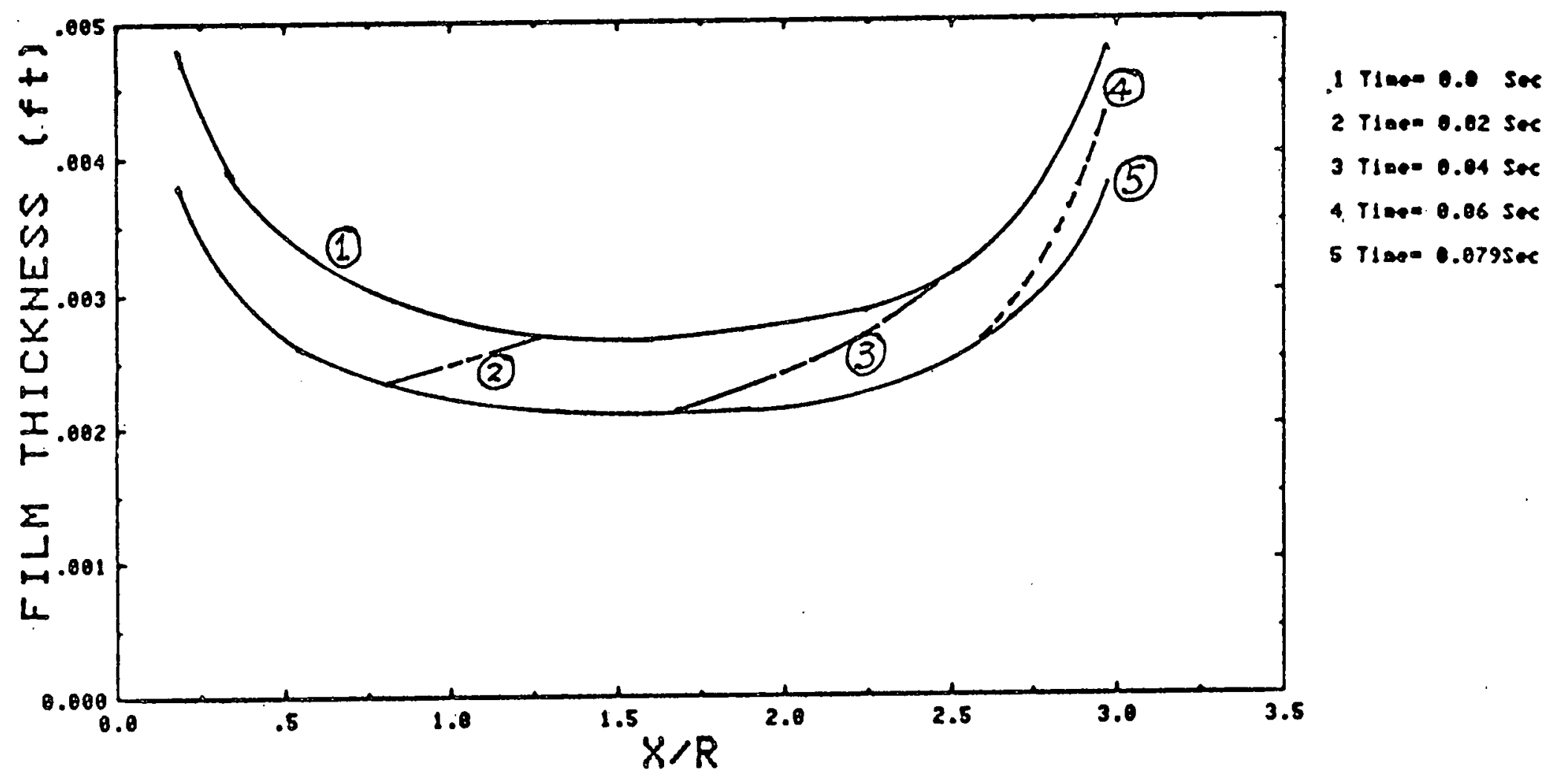

Figure A2 Step Reduce Flow Rate, No Heat Flux 


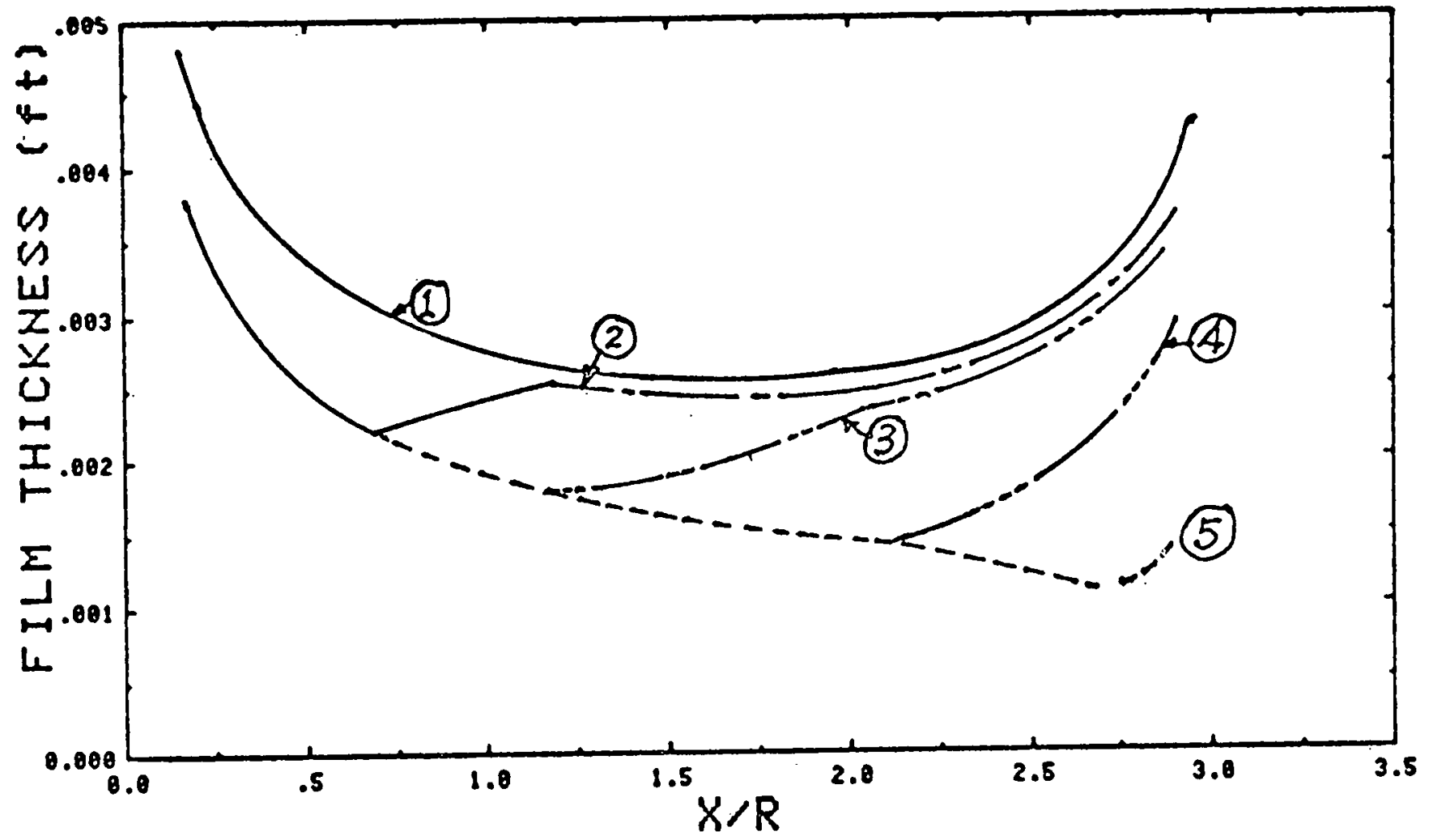

1 Tisee 0.0 Sec 2 Tiver 0.82 ser 3 Tlape 0.04 sec 4 Tloen 0.08 Sec 6 Tiaen 0.16 Sec

Figure A3 Ramp Reduce Flow Rate and Ramp Increase Heat Flux 
The most significant information is shown in Figure A4. With a step change of the input flow, the film thickness changes on lower tubes are shown versus time delay of the response as well as smoothing of the transients. For a tube bundle consisting of a hundred horizontal tubes the time delay will be significant and the transients w1ll be smoothed greatly. This type of detailed information obtained from the accurate analysis provides physical insights to the dynamic response of the film, and offers a reference to the lumped subsystem approach of the models. 

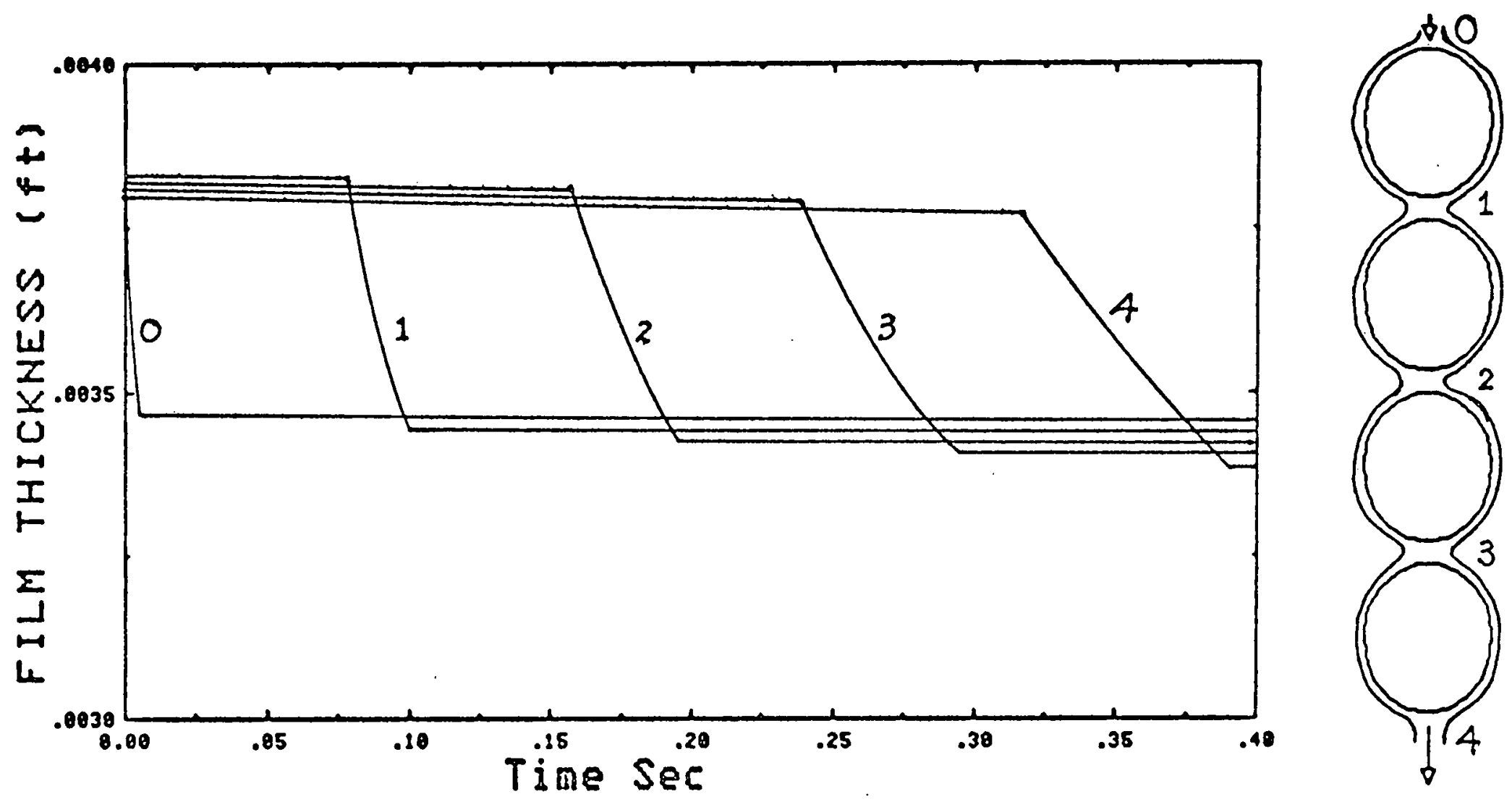

Figure A4 Evaporating $\mathrm{NH}_{3} \mathrm{Film}$ on 1 in O.D. Tube 
SEMI-ANNUAL PROGRESS REPORT

DOE CONTRACT NO. EY-76-S-02-2641

PART II

EXPERIMENT AND ANALYSIS

OF

HEAT TRANSFER AND FLUID FLOW

For Period

March 1, 1978 through August 31, 1978

\footnotetext{
Prepared by

Robert R. Rothfus Principal Investigator

Department of Chemical Engi neering

Carnegie-Mellon University

Pittsburgh, Pennsylvania 15213
} 
SEMI-ANNUAL PROGRESS REPORT

DOE CONTRACT NO. EY-76-S-02-2641

PART II

HEAT TRANSFER AND FLUID FLOW

\section{Introduction}

The projects performed under Contract EY-76-S-02-2641 are intended to provide engineering information that will reduce technical risks in design of OTEC heat exchangers, especially units of the vertical tube type, and dynamic control systems. The thermal and hydraulic aspects of heat exchanger design and R\&्षD are addressed in Part II of this semi-annual progress report. The program combines a balance of experimentation and analysis. Listed below are the tasks for these aspects of OTEC heat exchanger research:

1.0 Heat Transfer: Working Fluid Side and Water Side

1.1 Lengthen apparatus from $5 \mathrm{ft}$ to $14 \mathrm{ft}$ test length to establish the influence of length on the working fluid side heat transfer.

1.2 Run tests on smooth aluminum tubes to calibrate and check performance of apparatus.

1.3 Procure, install and run tests on corrugated $1^{\prime \prime}$ OD titanium tubes to obtain water-side and shell-side data. Test with $\mathrm{NH}_{3}$ and $R-11$ as working fluids. Distinguish she11-side from water-side heat transfer to furnish the basis for scale-up of geometrically dissimilar tubes.

1.4 Procure, install and run tests on corrugated $1^{\prime \prime}$ OD aluminum tubes with corrugations as near as possible to titanium corrugations of 1.3 , to establish effect of thermal conductivity of tube wall on heat transfer. 
1.5 Procure, install and run tests on extruded aluminum tubes of same design as tubes used in ANL core tests. Test working fluidside heat transfer with $\mathrm{NH}_{3}$ and $\mathrm{R}-11$. Distinguish she1l-side from water-side heat transfer to furnish the basis for scale-up of geometrically dissimilar tubes.

2.0 Fluid Flow on Shell Side to Resolve Effects of Geometrical Factors

2.1 Construct and test uniform bank with one pitch-to-diameter ratio, in-line array; measure pressure drop and velocity distribution without and with tributary (fluid lane) formed by omitting rows of tubes.

2.2 Construct in-line tube bank with variable pitch-to-diameter ratios to establish effect of pitch-to-diameter ratio on pressure drop in configurations without and with tributary.

2.3 Design and construct equilateral staggered tube bank and test without and with tributary to establish effect of fluid-stream orientation on the pressure drop.

2.4 Attempt to evolve an elementary continuum model for predicting flow patterns within tube banks of various shapes and examine these paths for maldistribution in projected OTEC heat exchangers.

3.0 Analys is of Argonne Core-Tests

Monitor tests of CMU heat exchangers at Argonne National Laboratory; reduce data, and compare these data with those of single-tube experimental data from CMU laboratory to furnish basis for scaleup to large multi-tube bundles. Examine water-side and ammoniaside behavior separately.

4.0 Dry-Out of Tubes Due to Drag

Design, construct and operate a new apparatus to test the effect 
of lateral drag on the peripheral distribution of falling liquid layers. Flow air normal to hot water over single, long, smooth and fluted tubes to assess potential dry-out in projected OTEC evaporators. If lateral movement is significant, select or develop experimental means of sensing dry-out in multi-tube units and conceptually design a double closed-loop anmonia apparatus to assess the cost and complexity of further experiments. 
1.0 Heat Transfer: Working Fluid Side and Water Side

\subsection{Lengthened apparatus}

In the previous contract year, from data on tubes of 5-ft length the investigators discerned that on the working fluid side both condensation and evaporation appeared to be strongly influenced by the particular way that waves developed along the tube. From visual observations it was noted that wave formations develop more slowly on fluted tubes than on smooth ones. This suggests the importance of determining heat transfer coefficients for tubes of more nearly prototypical lengths in order to predict full-scale performance. Consequently the experimental apparatus has been revised. The single-tube evaporator and single-tube condenser are still operated as a pair. But the active test length can now be made $14 \mathrm{ft}$ for 1 -inch and $1 \frac{1}{2}$-inch OD tubes and $12 \mathrm{ft}$ for 2 -inch $O D$ tubes. The previous test length was $5 \mathrm{ft}$ at the maximum. Data-logging capability has been added, so the computed results of each run are available immediately, before operating conditions are changed for the next test. Additional changes to apparatus are:

- to increase the pump capacity to accommodate greater load and to permit use of Wilson plot calculations

- to add and improve thermisters in order to study successive short sections of the condenser for measurement of "local" heat transfer

- to provide for installation of various applicators

- to tie in chiller to cool condenser water

- to make entire apparatus movable through 2-3 degrees from vertical to permit assessment of effect of tilt on heat transfer coefficients 


\subsection{Calibrate and Check Performance of Apparatus}

Check-runs using l-inch, 16 BWG, smooth aluminum tubes with $\mathrm{NH}_{3}$ as the working fluid have been completed and the data are in substantial agreement with those obtained previously on shorter tubes. That is, the mean heat transfer coefficient for ammonia exhibits the length dependence predicted by commonly accepted correlations in the open literature.

\subsection{Corrugated 1" OD Titanium Tubes}

Heat transfer coefficients have been measured on the working fluid side (outside) of single, vertical, axially fluted tubes used to evaporate or condense ammonia or R-11 on a 14-ft test length. Experiments have been completed or are projected on the following combinations:

Tube

Material

A1

A

Ti
Type of

Fluting

Area ratio 2.0

Crest dia. 40 mils

Rill dia. $40 \mathrm{mils}$

Area ratio 2.0 Crest dia. $40 \mathrm{mils}$

Rill dia. $60 \mathrm{mils}$

Corrugated with

28-mil wall.

22 flutes around periphery of tube, flute depth $47 \mathrm{mils}$
Tube

o.d.

$1 \frac{1}{4}$

inch

$1 \frac{1}{4}$

inch

1

inch

1

inch
Type of

Transfer

Evap.

and

Cond.

Evap.

and

Cond.

Evap.

and

Cond.
Working

Fluid

$\mathrm{NH}_{3}$ and

R-11
$\mathrm{NH}_{3}$ and R-11
Corrugated with 28-mil wall.

22 flutes around periphery of tube, flute depth $47 \mathrm{mils}$
Evap. and Cond.

$\mathrm{NH}_{3}$ and R-11 
The first two tubes in the above list are like those in the core test units at Argonne. The third and fourth tubes are identical except for material. The third tube, being of aluminum, can be tested with only R-11 since it cannot withstand the pressure of $\mathrm{NH}_{3}$.

Water side and working fluid side data have been separated by means of the classical Wilson plot. Especially in tests of titanium tubes, the difficulty of obtaining meaningful wall temperatures on corrugated surfaces makes it almost mandatory to back out the water side resistance through this kind of calculation. As presently constructed the apparatus allows water side and ammonia side data to be obtained simultaneously and separate water side experiments have thus far proved unnecessary.

The working fluid side data are being correlated in terms of lengthmean heat transfer coefficients. In the condenser it is possible to examine the heat transfer over short sections of the $14 \mathrm{ft}$ test length. Therefore it is possible to obtain the length mean coefficient between the top of the unit and intermediate points along the length. In all cases the coefficient reported for the working fluid side is actually a composite coefficient which includes the resistance of both the tube wall and the falling layer of liquid working fluid.

To date experiments using ammonia as the working fluid have been completed on the corrugated titanium tube with 22 flutes around its periphery and also on the extruded aluminum tubes having flutes with a crest diameter of $40 \mathrm{mils}$ and a rill diameter of 40 mils. Both types of aluminum tubes have been tested as evaporators and condensers.

The experimental data show the extruded aluminum tube to be superior to the titanium tube, both in evaporation and in condensation. This appears to be the case even when normal conduction through the tube wall 
is taken into account. The investigated style of aluminum tube when in service as an evaporator shows peak enhancement of heat transfer in the region of laminar-turbulent transition. The peak coefficient is about $8000 \mathrm{Btu} /(\mathrm{hr})\left(\mathrm{ft}^{2}\right)\left({ }^{\circ} \mathrm{F}\right)$ while at high loadings of liquid the coefficient is at about $3000 \mathrm{Btu} /(\mathrm{hr})\left(\mathrm{ft}^{2}\right)\left({ }^{\circ} \mathrm{F}\right)$. When used as a condenser, the same tube exhibits coefficients of 10,000 or more at low liquid loadings and of $3000-$ 4000 at high loadings. Measurements over short sections of the condenser suggest that there is an effect of tube length (or heat flux) on the mean heat transfer coefficient. This is being examined currently.

Water side coefficients of heat transfer have been measured at the same time as were the working fluid coefficients. The data indicate that the enhancement of heat transfer by the factor of the fluted-to-smooth area ratio or somewhat more can be obtained at water velocities typical of projected OTEC applications. 


\subsection{Fluid Flow on Shel1 Side to Resolve Effects of Geometrical Factors \\ 2.1 and 2.2 Shell-Side Pressure Drop}

To prevent maldistribution of fluid in OTEC exchangers of the vertical tube type, shell-side pressure drop has to be rendered insignificant. Evaporators and condensers are unlike the usual heat exchanger, since there is generation or depletion of vapor at each tube site. Pressure drop data in the open literature do not deal with such cases, nor do they clearly establish the pressure drop in closely packed tube bundles such as the ones projected for OTEC use.

To clarify shell-side behavior, experiments have been performed on in-line tube banks of quarter scale using hot water to simulate ammonia vapor. In equipment of this scale hot water permits almost identical Reynolds numbers for water and ammonia to be attained at substantially the same linear fluid velocity. The experimental tube banks have a large number of tubes in each longitudinal row and provision is made for altering the pitch-to-diameter ratio of the array in both the transverse and longitudinal directions. In one of the experimental tube banks porous tubes permit the generation of fluid at each tube site to be simulated. A practical means of reducing she11-side pressure drop is to remove one or more longitudinal rows of tubes, thus forming a fluid lane; the experimental apparatus is designed to permit such tributaries to be formed.

Experiments have been completed on a square in-line array having a pitch-to-diameter ratio of 1.77 . This bank has been tested with and without fluid generation at each tube. Data on this bank indicated that the pressure drop without generation is adequately correlated by commonly used equations such as those of Jakob and Gunter and Shaw. The data also indicated that in the case of generation, the once-through equations can be applied at each 
tube site and can be integrated along the length of the bank without introducing additional error. This means that unless large transverse pressure gradients are present, correlations of once-through data can be used to predict the corresponding cases of generation.

In order to assess the effects of boundaries along the sides of a tube bank, a wider bank containing up to 12 longitudinal channels has been constructed, operating on a once-through basis. At the downstrean end of this bank there is provision for the measurement of fluid velocities at several points across the width of the bank. This permits correlation of pressure drop with velocity for individual fluid lanes within the bank. This bank is so arranged that transverse ratios of $1.25,2.5$, and 3.75 , and longitudinal pitch-to-diameter ratios of the same three values can be tested in the in-line mode and in any combination of the longitudinal and transverse pitch-to-diameter ratios just listed. A central tributary of predetermined transverse width can be formed by the removal of 1, 2 or 3 longitudinal rows. This permits investigation of tributaries having transverse pitch-to-diameter ratios up to 5 .

Data have thus far been obtained in the square in-line array having a pitch-to-diameter ratio of 1.25 . This ratio is typical of the smallest ratio projected for full scale OTEC use. The data indicate that most correlations in the open literature are too conservative at this low pitch-todiameter ratio. That is, they predict too high a pressure drop.

Preliminary data on pressure drop through tributaries in this bank also indicate that correlations based on pressure drop in uniformly spaced arrays are not adequate to represent the tributary.

Experiments will be continued until all possible combinations of pitch-to-diameter ratio and tributary width have been examined in the inline mode. 


\subsection{Equilateral Staggered Tube Bank}

A tube bank similar to the one just described is being constructed in order to test the effect of orientation on the pressure drop. This bank will be operated in the staggered mode with the tubes on equilateral triangular centers as viewed by the flowing fluid. Comparison of the inline and staggered arrays will form the basis for a preliminary assessment (task 2.4) of probable flow paths through the shell side of a large OTEC exchanger.

\subsection{Analysis of Argonne Core-Tests}

In 1977, two heat exchangers of nominal $3.2 \times 10^{6}$ (maximum $4 \times 10^{6}$ ) $\mathrm{Btu} / \mathrm{hr}$ capacity were designed, fabricated and delivered to the Argonne site for core-testing. The units were thermally and hydraulically designed by Carnegie-Mellon, designed for bid by the Aluminum Company of America and finally designed and built by the Foster Wheeler Energy Company.

The exchangers are identical except for the details of the ammoniaside flutes. They both contain 240 tubes with an effective heat-transfer length of slightly more than 14 feet. Both are of vertical tube design and both can be tested as either an evaporator or a condenser. Both contain doubly-fluted tubes of nominal 1 -inch size with 60-mil high internal flutes. The external flutes are $40 \mathrm{mils}$ high with 40 -mil crest diameter. One unit (nominally the evaporator) has 40-mil rill diameter and the other (nominally the condenser) has 60-mil rill diameter of these outside flutes.

As they have become available, data from the Argonne tests have been analyzed and compared with single-tube data obtained at Carnegie-Mellon University.

Heat Transfer coefficients from the water side and ammonia side of the fluted heat transfer surfaces have been separated through computation. 
Consistent with the single-tube data obtained in this laboratory, ammonia coefficients have been calculated as composite coefficients which include the resistances of the tube wall and liquid ammonia layer. In cases where the Argonne data have permitted the construction of Wilson plots, the individual coefficients on the two sides of the heat transfer surface have been separated in that manner.

In a few cases where data did not permit the Wilson plot to be drawn, water-side coefficients obtained from single tube experiments were assumed to apply and ammonia-side coefficients were obtained by difference. To date only preliminary information on the evaporator is available but analysis of these data tentatively indicate that the unit is performing up to expectations. Further testing is necessary before the operating conditions which yield maximum performance can be established.

The vertical condenser having external flutes with a crest diameter of $40 \mathrm{mils}$ and a rill diameter of $60 \mathrm{mils}$ has been tested over the whole prescribed range of operating conditions in a total of about 90 runs. Overall coefficients range from 810 to $1800 \mathrm{Btu} /(\mathrm{hr})\left(\mathrm{ft}^{2}\right)\left({ }^{\circ} \mathrm{F}\right)$, depending on the water velocity, which ranged from 2.5 to $12.3 \mathrm{ft} / \mathrm{sec}$. Both the water-side and the ammonia-side coefficients appear to be in close agreement with the single-tube laboratory data. This indicates that vertical-tube condensers with tube bundles of modest size can be scaled up directly from single-tube data.

\subsection{Dry-Out of Tubes Due to Drag}

On the basis of elementary analyses done at Carnegie-Mellon, there is reason to believe that a falling liquid layer on the exterior of a vertical tube may be moved significantly around the periphery by the drag of 
vapor flowing normal to the tube. On long tubes, this may result in dry-out of the side exposed to the vapor before the liquid can reach the bottom. Although initial analysis was limited to laminar, waveless flow on a smooth tube, it suggested that a liquid of low viscosity, such as ammonia, may be moved significantly by a vapor velocity of about one foot per second. In contrast, steam would cause the same movement of liquid at about four feet per second.

When external flutes are present, the rills should retain liquid even at high vapor velocities, but the crests are apt to be vulnerable. If waves can no longer wash the crests, an adverse effect may result in the evaporator (and perhaps a favorable one in the condenser). There is no way to resolve this concern except through experiment.

To assess whether dry-out due to lateral movement of the liquid layer may be a problem in OTEC evaporators, an experimental unit has been designed for use with air and water. A single vertical tube of about 15 foot test length has a continuous liquid film applied to its exterior surface at the top of the unit. The falling liquid film is exposed to a cross flow of vapor carefully regulated so as to be constant over the whole length of the tube. The clearance for the vapor at the entrance and exit and in the space around the tube is of such size as to approximate conditions in a tube bank with a 1.25 pitch-to-diameter ratio. The vapor path is so designed that the scale of turbulence in the vicinity of the experimental tube is approximately equal to that impinging on an individual tube in a full scale tube bank.

The test sections and supporting framework are being constructed. The entire test section is of clear plastic so that visual observation of dry-out can be made along the entire length of the apparatus. The first test section to be constructed accommodates a $1 \frac{1}{4}$ - inch smooth aluminum 
$-89-$

13

tube or the corresponding extruded aluminum fluted tube of the design used in the Argonne core tests. Provision is made for control of both vapor and liquid flow rates to cover the range of velocities of most interest for OTEC applications. These preliminary tests on air and water are merely intended to show whether a dry-out problem is apt to exist in full-scale evaporators.

WU.S. GOVERNMENT PRINTING OFFICE: 1979-fAn-n9?/G96 